\title{
COMPARATIVO DOS REGIMES DE ICMS NO ESTADO MATO GROSSO: UMA ANÁLISE TÉCNICA ${ }^{1}$
}

\author{
Varlindo Alves da Silva ${ }^{2}$, Jonas Costa da $\mathrm{Cruz}^{3}$, Paulo Sérgio Almeida-Santos ${ }^{4}$
}

\section{RESUMO}

Comparar tecnicamente de modo objetivo os diversos regimes de ICMS em Mato Grosso, imposto de maior receita absoluta da federação, é a que este trabalho tem como objetivo geral. Por ser um imposto indireto, ou seja, "invisível" para o consumidor, destrinchá-lo é substancial para que os contribuintes de fato saibam quanto e o que estão pagando, bem como o empresário consiga otimizar o seu planejamento tributário. $\mathrm{O}$ presente foi elaborado com vistas à legislação vigente, bem como a doutrinas e, também, foi realizado um estudo de caso com tabelas e gráficos para melhor visualização dos resultados. Portanto, este estudo, na sua conclusão, auxilia o empresário a optar pelo melhor regime de ICMS em Mato Grosso conforme a sua atividade, a sua margem de lucro e também o seu faturamento.

Palavras-chave: ICMS. Regimes de tributação. Gestão de tributos. Estado de Mato Grosso.

\section{COMPARATIVE OF ICMS TAX REGIMES IN THE STATE MATO GROSSO: AN TECHNICAL ANALYSIS}

\begin{abstract}
Compare objectively the different ICMS regimes in Mato Grosso, the largest absolute revenue of the federation tax, is that this work provides. Because it is an indirect tax, that is "invisible" to the consumer, unpacks it is fundamentally important both to the fact that taxpayers know how much and what they are paying, and for the entrepreneur can optimize your tax planning. This was drawn up with a view to current legislation and the doctrines and, also, there was a case study with tables and charts for best viewing results. Therefore, this study in its conclusion, helps the entrepreneur to choose the best ICMS system according to your activity, your profit margin and your billing.

Keywords: ICMS. Taxation schemes. Tax management. States of Mato Grosso.
\end{abstract}

\section{INTRODUÇÃO}

A complexidade da legislação concernente ao imposto de Circulação de Mercadorias e Sobre Prestações de Serviços de Transporte Interestadual e Intermunicipal e de Comunicação (ICMS), muitas vezes faz com que o contribuinte não analise a melhor forma de apurar o imposto a ser pago, optando, dessa forma, pela

\footnotetext{
${ }^{1}$ Os autores são gratos aos avaliadores anônimos pelos preciosos comentários e também ao Editor Prof. Laércio Juarez Melz pela presteza na condução da avaliação e publicação deste trabalho.

${ }^{2}$ Universidade Federal do Mato Grosso - FACC.

${ }^{3}$ Universidade Federal do Mato Grosso - FACC.

${ }^{4}$ Universidade de Brasília - PPGCONT e Universidade Federal de Mato Grosso - FACC.
} 
apuração mais descomplicada. Nesta perspectiva, diante das diversas formas de apuração presente em Mato Grosso, por exemplo, torna-se necessário que os empresários analisem os regimes e optem pelo mais benéfico. Dessa forma, faz-se necessário que os profissionais da área tributária, mais precisamente os contadores façam uma análise da melhor forma de tributação para cada empresa.

Este trabalho tem o objetivo de apresentar e comparar tecnicamente os diversos regimes de apuração do ICMS no Estado de Mato Grosso, em especial os Regimes: Normal, Estimativa Simplificado, Simples e Diferencial de Alíquota. Assim, a partir de uma pesquisa descritiva e bibliográfica, principalmente remetendo-se à legislação, pretende-se analisar o ICMS através do tempo até 2013 (alteração mais recente), buscando-se compreender a sua sistemática e suas diversas formas de apuração.

Ademais, o presente trabalho é composto de três seções, sendo que na Seção I abordaremos o ICMS de forma abrangente; na Seção II, o ICMS em Mato Grosso; e na Seção III é apresentado um estudo de caso compilando os conhecimentos apresentados.

Não obstante, não se pretende com este trabalho esgotar esse assunto, pois, além da sua complexidade, tal tributo está presente direto e indiretamente na vida de toda sociedade e a cada dia surgem novas normas que podem tornar este estudo obsoleto, embora ele sempre seja atual na sua essência.

\section{DO ICMS GERAL}

O Imposto sobre Operações relativas à Circulação de Mercadorias e Sobre Prestações de Serviços de Transporte Interestadual e Intermunicipal e de Comunicação (ICMS) está previsto no Art. 155, II e $\S \S 2^{\circ}$ a $5^{\circ}$, da atual Constituição Federal.

De competências dos Estados e do Distrito Federal, tal tributo é a principal fonte de receita para os entes competentes a instituí-lo, e segundo estudo do economista José Roberto Rodrigues Afonso (2013) para a FGV, a carga do ICMS somou 7,45\% do PIB em 2012, o que representa quase R $\$ 330$ bilhões.

Ainda nesse aspecto, deve-se considerar a importância da arrecadação do ICMS para os municípios, tendo em vista o que está consignado no Art. 158, IV da CF: 
Art. 158. Pertencem aos Municípios: (EC no 42/2003)

IV - vinte e cinto por cento do produto da arrecadação do imposto do Estado sobre operações relativas à circulação de mercadorias e sobre prestações de serviços de transporte interestadual e intermunicipal e de comunicação. (CF)

De acordo com BORBA (2013, p. 149), o ICMS que conhecemos hoje "surgiu de uma unificação de seis outros existentes no ordenamento jurídico anterior". Ou seja, a CF de 1988 criou este único imposto com a junção de outros impostos já previstos na CF de 1967. Observemos tal junção dos impostos na Figura 1 e Quadro 1 que seguem:

Figura 1 - Unificação do ICMS

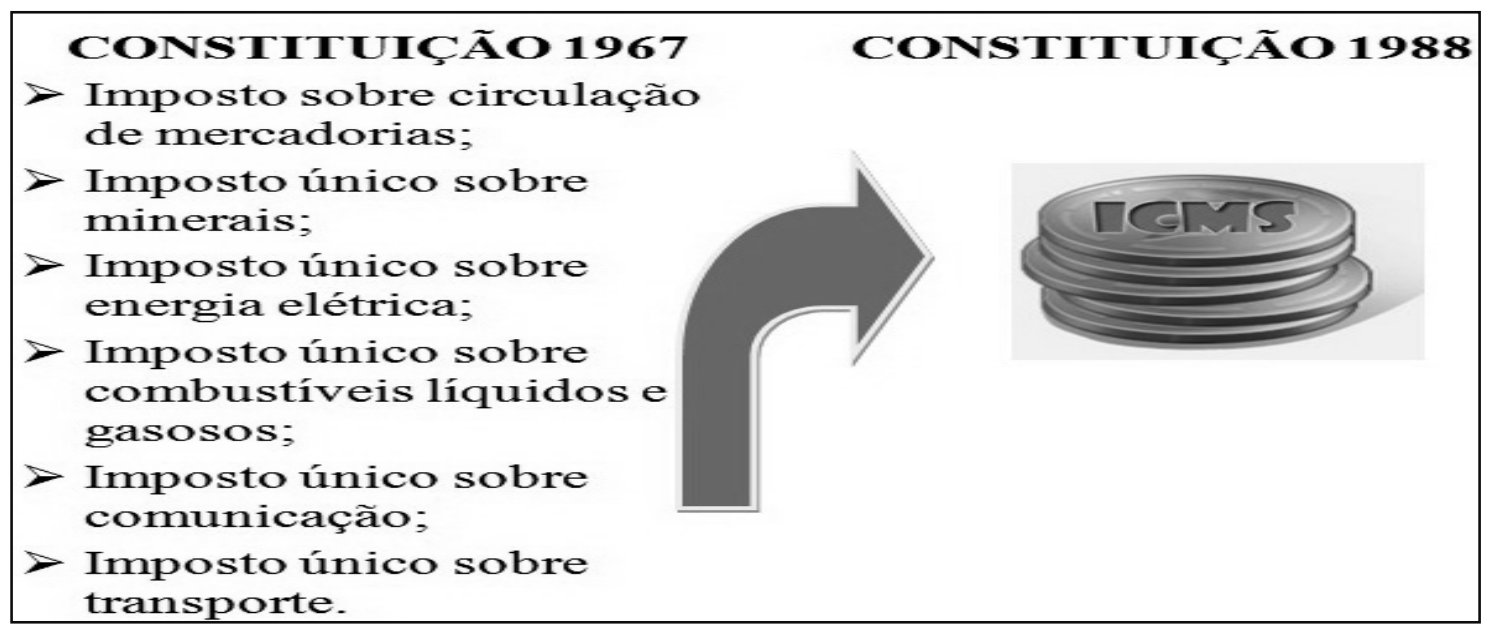

Fonte: elaboração própria.

Quadro 1 - Unificação do ICMS

\begin{tabular}{|l|c|}
\hline \multicolumn{2}{|c|}{ COMPETÊNCIA TRIBUTÁRIA SEGUNDO CONSTITUIÇÃO DE 1967 } \\
\hline \multicolumn{1}{|c|}{ IMPOSTO } & COMPETENCIA \\
\hline Imposto sobre circulação de mercadorias & Estados e DF \\
\hline Imposto único sobre minerais & União \\
\hline Imposto único sobre combustíveis líquidos e gasosos & União \\
\hline Imposto único sobre energia elétrica & União \\
\hline Imposto único sobre transportes (exceto municipal) & União \\
\hline Imposto único sobre comunicações & União \\
\hline
\end{tabular}

Fonte: elaboração própria.

Sendo assim, vale-se destacar que o ICMS é considerado um tributo complexo devido aos diversos fatos geradores previstos, resultante da compilação de diversos outros impostos. Ademais, mais normas a respeito deste imposto podem ser encontradas na LC n 87/1996 (Lei Kandir), bem como, em âmbito estadual, na Lei Estadual de 
Mato Grosso $n^{\circ}$ 7098/98. No entanto, o emaranhado de legislação não se esgota apenas na CF, na Lei Kandir e na Lei 7098/98 - MT.

\section{INCIDÊNCIA}

Ao longo da sua história, as hipóteses de incidência do ICMS foram abrangendo cada vez mais fatos geradores de modo que hoje podemos considerá-lo um imposto complexo. Desde o IVM (Imposto Sobre Vendas Mercantis), passando pelo IVC (Imposto Sobre Vendas e Consignações) e ICM (Imposto Sobre Circulação de Mercadorias) até chegarmos ao ICMS (Imposto Sobre Circulação de Mercadorias e Serviços), o legislador foi alterando as normas tanto para incrementar as receitas públicas quanto para retirar e atribuir competência entre os entes federativos, visto que este imposto a princípio era de competência da União e hoje a competência para instituílo é dos EM e DF.

$\mathrm{Na}$ corrente Constituição a principal alteração em relação ao texto anterior, na hipótese de incidência do ICMS, foi à inclusão de "prestação de serviço de transporte interestadual e intermunicipal e de comunicação, ainda que as operações e as prestações se iniciem no exterior" (CF).

Além da CF, a incidência do ICMS pode ser observada tanto na Lei Kandir quanto na Lei Estadual de MT nº 7.098/1998. Consigna o Art. $2^{\circ}$ da Lei 7.098/98 que:

"Art. $2^{\circ} \mathrm{O}$ imposto incide sobre:

I - operações relativas à circulação de mercadorias, inclusive fornecimento de alimentação e bebidas em bares, restaurantes e estabelecimentos similares;

II - prestações de serviços de transporte interestadual e intermunicipal, por qualquer via, de pessoas, bens, mercadorias ou valores;

III - prestações onerosas de serviços de comunicação, por qualquer meio, inclusive a geração, a emissão, a recepção, a transmissão, a retransmissão, a repetição e a ampliação de comunicação de qualquer natureza;

IV - fornecimento de mercadorias com prestação de serviços não compreendidos na competência tributária dos Municípios;

$\mathrm{V}$ - fornecimento de mercadorias com prestação de serviços sujeitos ao imposto sobre serviços, de competência dos Municípios, quando a lei complementar aplicável expressamente o sujeitar à incidência do imposto estadual.

$\S 1^{\circ} \mathrm{O}$ imposto incide também:

I - sobre a entrada de bem ou mercadoria importados do exterior por pessoa física ou jurídica, ainda que não seja contribuinte habitual do imposto, qualquer que seja a sua finalidade; 
II - sobre o serviço prestado no exterior ou cuja prestação se tenha iniciado no exterior;

III - sobre a entrada, no território do Estado, de petróleo, inclusive lubrificantes e combustíveis líquidos e gasosos dele derivados, e de energia elétrica, quando não destinados à comercialização ou à industrialização e decorrente de operações interestaduais;

IV - sobre a entrada no estabelecimento de contribuinte de bem ou mercadoria destinada a uso, consumo ou ativo permanente;

IV-A - sobre a operação, realizada por remetente de outra unidade federada, que destinar bem ou mercadoria ao consumidor final, não contribuinte do imposto, localizado no território mato-grossense; (Acrescentado pela Lei $10.337 / 15$, efeitos a partir de $1 \% 01 / 2016$ )

V - sobre a utilização, por contribuinte, de serviço cuja prestação se tenha iniciado em outro Estado e não esteja vinculada a operação ou prestação subsequente;

V-A sobre a prestação de serviço, iniciada em outra unidade federada, destinada a consumidor final, não contribuinte do imposto, localizado no território mato-grossense; (Acrescentado pela Lei 10.337/15, efeitos a partir de $1 \%$ (01/2016)

VI - sobre as operações com programa de computador - software -, ainda que realizadas por transferência eletrônica de dados."

Em relação aos incisos IV e V do Art. 2º, BORBA, (2013) aborda didaticamente no quadro a seguir:

Figura 2 - Incidência do ICMS

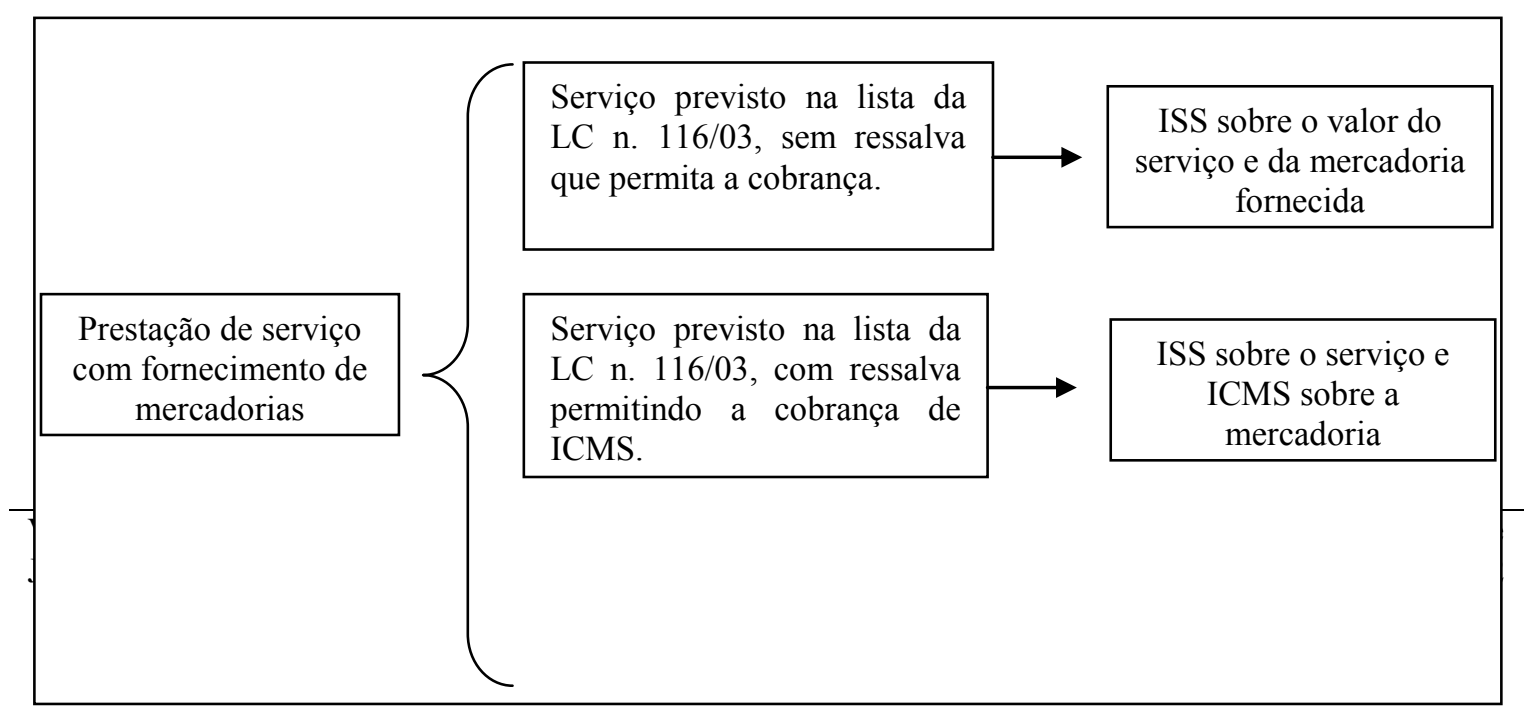




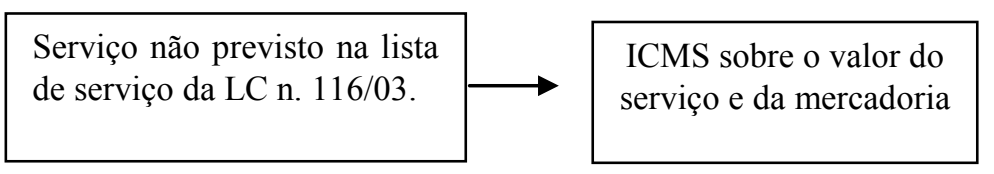

Fonte: Borba (2013, p. 180)

Todavia, nos termos da Lei No. 7.098/98, as hipóteses de incidência do ICMS ainda são mais abrangentes. Nota-se ainda que o imposto incida sobre importação de bens ou mercadorias do exterior; serviço prestado ou iniciado sua prestação no exterior; entrada de petróleo e seus derivados em território mato-grossense, bem como a energia elétrica quando não destinados à comercialização ou industrialização; bem ou mercadorias entradas no estabelecimento de contribuinte destinado a uso, consumo ou ativo permanente; dentre outras hipóteses.

Ainda no Art. $2^{\circ}$ da Lei 7.098/98, vale-se ressaltar que, o seu $\S 5^{\circ}$ consigna: "a caracterização do fato gerador independe da natureza jurídica da operação que o constitua". (Lei 7.098/98 - MT). Ou seja, como escrevera Borba (2013, p. 182):

“[...] a operação de circulação de mercadoria pode ser devida à doação, troca, devolução, qualquer ato jurídico que caracterize troca de titularidade de mercadorias ou qualquer outra forma de circulação, ressalvada as hipóteses previstas nesta lei ou em convênios entre Estados e Distrito Federal. [...].”

Embora haja um emaranhado de legislação tratando desse imposto, as hipóteses de incidência é assunto de inovação exclusiva da CF.

\section{BASE DE CÁLCULO}

Podemos considerar que a base de cálculo de um imposto é a quantia em que se aplica a alíquota para apurar o imposto a pagar. Assim sendo, Ataliba (1992) conclui que:

“[...] Base de cálculo é a perspectiva dimensional do aspecto material da hipótese de incidência que a lei qualifica, com a finalidade de fixar critério para determinação, em cada obrigação concreta, do quantum debeatur. Segundo seu entendimento: A base imponível é ínsita á hipótese de incidência. É atributo essencial, que, por isso, não deixa de existir em caso algum $[\ldots] . "$ 
Portanto, a base de cálculo é atributo substancial para apuração do valor do ICMS. Borba (2013) consignou em sua obra um quadro resumindo o Art. 13 da Lei Kandir:

\section{Quadro 2 - Delineamento da Lei Kandir}

\begin{tabular}{|c|c|c|}
\hline Lei Kandir & Fato Gerador & Base de Cálculo \\
\hline Art. 13, I & $\begin{array}{l}\text { Saída de mercadoria de estabelecimento } \\
\text { contribuinte, ainda que para outro estabelecimento do } \\
\text { mesmo titular. }\end{array}$ & \multirow{3}{*}{ O valor da operação } \\
\hline Art. 13, I & 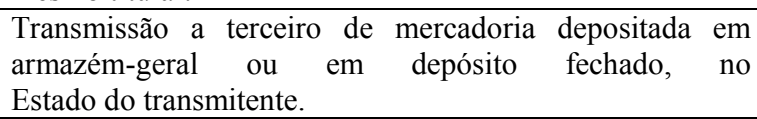 & \\
\hline Art. $13, \mathrm{I}$ & $\begin{array}{l}\text { Transmissão de propriedade de mercadoria, ou de título } \\
\text { que a represente, quando a mercadoria não tiver transitado } \\
\text { pelo estabelecimento transmitente. }\end{array}$ & \\
\hline Art. 13, II & $\begin{array}{l}\text { Fornecimento de alimentação, bebidas e outras } \\
\text { mercadorias por qualquer estabelecimento. }\end{array}$ & $\begin{array}{l}\text { O valor da operação, compreendendo } \\
\text { mercadoria e serviço. }\end{array}$ \\
\hline Art. 13, III & $\begin{array}{l}\text { Prestação de serviço de transporte interestadual e } \\
\text { intermunicipal e de comunicação. }\end{array}$ & O preço do serviço. \\
\hline Art. 13, IV, $a$ & $\begin{array}{l}\text { Do fornecimento de mercadoria com prestação } \\
\text { de serviços não compreendidos na competência tributária } \\
\text { dos Municípios. }\end{array}$ & O valor total da operação. \\
\hline Art. $13, \mathrm{IV}, b$ & $\begin{array}{l}\text { Do fornecimento de mercadoria com prestação de serviço } \\
\text { compreendidos na competência tributária dos Munícipios } \\
\text { e com indicação expressa de } \\
\text { incidência do imposto de competência estadual, como } \\
\text { definido na lei complementar aplicável. }\end{array}$ & $\begin{array}{l}\text { O preço corrente da mercadoria } \\
\text { fornecida ou empregada. }\end{array}$ \\
\hline
\end{tabular}

Continua...

\begin{tabular}{|c|c|c|}
\hline Lei Kandir & Fato Gerador & Base de Cálculo \\
\hline Art. $13, \mathrm{~V}$ & Importação de mercadoria no exterior. & $\begin{array}{l}\text { A soma das seguintes parcelas: } \\
\text { a) o valor da mercadoria ou bem } \\
\text { constante dos documentos de } \\
\text { importação observado o disposto } \\
\text { no art. 14;b) II, IPI, IOF; c) quaisquer } \\
\text { despesas aduaneiras. }\end{array}$ \\
\hline Art. 13, VI & $\begin{array}{l}\text { Recebimento, pelo destinatário, de serviço prestado no } \\
\text { exterior; }\end{array}$ & $\begin{array}{l}\text { O valor da prestação do serviço } \\
\text { acrescido, se for o caso, de todos } \\
\text { os encargos relacionados com a } \\
\text { sua utilização. }\end{array}$ \\
\hline Art. 13, VII & $\begin{array}{l}\text { Aquisição em licitação pública de mercadorias } \\
\text { importadas do exterior apreendidas ou abandonadas. }\end{array}$ & $\begin{array}{l}\text { O valor da operação acrescido do } \\
\text { valor do II e do IPI e de todas } \\
\text { as despesas cobradas ou debitadas ao } \\
\text { adquirente. }\end{array}$ \\
\hline Art. 13, VIII & $\begin{array}{l}\text { Entrada no território do Estado de lubrificantes e } \\
\text { combustíveis líquidos e gasosos derivados de } \\
\text { petróleo e energia elétrica oriundos de outro Estado } \\
\text { quando não destinados à comercialização ou à } \\
\text { industrialização. }\end{array}$ & $\begin{array}{l}\text { O valor da operação de que } \\
\text { decorrer a entrada. }\end{array}$ \\
\hline Art. 13, IX & $\begin{array}{l}\text { Utilização, por contribuinte, de serviço cujaprestação se } \\
\text { tenha iniciado em outro Estado enão esteja vinculada à } \\
\text { operação ou prestação subsequente. }\end{array}$ & $\begin{array}{l}\text { O valor da prestação no Estadode } \\
\text { origem. }\end{array}$ \\
\hline
\end{tabular}


Fonte: Borba (2013).

\subsection{REGIME DE APURAÇÃO NORMAL}

O Regime de Apuração Normal do ICMS está disciplinado na Seção II, Art. 78 e 79 do RICMS (Regulamento do ICMS). Tal regime de apuração é o mais comum no país, sendo que a sua principal característica é apuração do crédito na entrada da mercadoria e o débito na saída. Logo, caso os créditos forem maiores que os débitos o contribuinte gozará de Impostos a Recuperar junto ao fisco, sendo que se os débitos forem maiores que os créditos o contribuinte terá Imposto a Pagar.

A sistemática de apuração das entradas e saídas está fundamentada no Art. 78, incisos I e II do RICMS:

“Art. 78 Os estabelecimentos enquadrados no regime de apuração normal apurarão no último dia de cada mês:

I - no Registro de Saídas:

a) o valor contábil total das operações e/ou prestações;

b) o valor total da base de cálculo das operações e/ou prestações com débito do imposto e o valor do respectivo imposto debitado;

c) o valor fiscal total das operações e/ou prestações isentas ou não tributadas;

d) o valor fiscal total de outras operações e/ou prestações sem débito do imposto;

II - no Registro de Entradas:

a) o valor contábil total das operações e/ou prestações;

b) o valor total da base de cálculo das operações e/ou prestações com crédito do imposto e o valor total do respectivo imposto creditado;

c) o valor fiscal total das operações e/ou prestações isentas ou não tributadas;

d) o valor fiscal total de outras operações e/ou prestações sem crédito do imposto;

e) o valor total da diferença do imposto devido a este Estado, decorrente da entrada ou aquisição das mercadorias oriundas de outra unidade federada, destinadas a uso, consumo ou ativo fixo, e da utilização de serviço cuja prestação não esteja vinculada à operação ou prestação subsequente alcançada pela incidência do ICMS."

Cabe-se ressaltar que, conforme consignado na alínea "e" supracitada, caso a mercadoria seja adquirida em operação interestadual para o uso, consumo e ativo fixo do contribuinte, este deverá calcular e recolher separadamente o imposto, em código específico, com a denominação "Diferencial de alíquota recolhido no mês".

No caso da Apuração Normal, alíquota aplicável às mercadorias adquiridas de outras UFs destinadas ao uso, consumo e ativo permanente será a diferença entra a 
alíquota interna do estado e alíquota aplicada no estado de origem, conforme Art. 50, inciso II do RICMS:

\footnotetext{
“Art. 50. Quanto à alíquota, deverão, ainda, ser observadas as seguintes regras:

II - na entrada no estabelecimento de contribuinte de bem ou mercadoria, adquirida em outra unidade federada, destinada a uso, consumo ou ativo permanente, bem como na utilização, por contribuinte, de serviço cuja prestação se tenha iniciado fora do território mato-grossense e não esteja vinculada à operação ou prestação subsequente, alcançada pela incidência do imposto, a alíquota será o percentual que resultar da diferença entre a alíquota interna deste Estado, aplicável à operação ou à prestação, e aquela aplicada na unidade federada de origem da mercadoria ou serviço para operação ou prestação interestadual."
}

Desse modo, no caso das entradas de mercadorias destinadas a uso, consumo e ativo permanente adquiridas de outros estados teremos dois tratamentos em relação ao ICMS. Isto, pois, esta mercadoria não será objeto de operação ou prestação subsequente, tão somente fará parte do ativo fixo da empresa. Então, teremos um crédito, resultante do imposto destacado na nota fiscal, como também teremos um imposto a pagar denominado Diferencial de Alíquota, resultante da diferença entre a alíquota interna do Mato Grosso e a alíquota aplicada no estado de origem da mercadoria.

No entanto, embora haja um crédito a ser compensado, este deverá ser apropriado na proporção de "um quarenta a oito avos por mês, devendo a primeira fração ser apropriada no mês em que ocorrer a entrada no estabelecimento" (Art. 25, § $4^{\circ}$, I da Lei 7.098/98).

Conforme já dito, o ICMS deve considerar o princípio constitucional da nãocumulatividade, sendo compensados os créditos na entrada com os débitos da saída, em se tratando de operação relativa à circulação de mercadoria ou prestação de serviços.

\subsection{REGIME DE APURAÇÃO ESTIMATIVA SIMPLIFICADO}

A Estimativa Simplificada é um regime de apuração do ICMS introduzido no RICMS pelo Decreto $n^{\circ}$ 392/2011. A motivação para tal decreto surgiu, segundo seu texto, para melhorar a eficiência nos controles tributários, como também contribuir para a simplificação dos procedimentos, tanto para o fisco quanto para o contribuinte. 
Ademais, a legalidade do decreto está consignada no Art. 30, inciso V, alínea "b", da Lei $n^{\circ} 7.098 / 98$ :

\footnotetext{
“Art. 30 Em substituição ao regime mencionado nos artigos 28 e 29, a apuração do imposto poderá ser efetuada, também, através:

$\mathrm{V}$ - de regime de estimativa por operação ou prestação, nos termos do regulamento e normas complementares, cuja tributação poderá, cumulativa ou alternativamente, objetivar: (Nova redação dada pela Lei 9.226/09).

b) a simplificação, mediante exigência baseada na carga tributária média e eventual encerramento da fase tributária."
}

Então, este regime está regulamentado nos Art. 87-J-6 a 87-J-17 do RICMS e seus efeitos são para os fatos geradores ocorridos a partir de $1^{\circ}$ de junho de 2011. Para tanto, o Decreto no 392/2011 também introduziu o Anexo XVI no RICMS, conhecido como "percentual de carga média por CNAE, para fins de aplicação do Regime de Estimativa Simplificado". (Anexo XVI do RICMS).

Em síntese, a sistemática deste regime é aplicar uma carga média (contida no Anexo VI do RICMS) estabelecida pela Secretaria da Fazenda (SEFAZ) de acordo com a Classificação Nacional de Atividades Econômicas (CNAE) principal do contribuinte sobre a base de cálculo do imposto. É aplicada esta sistemática a todos os contribuintes pertencentes a este regime em todas as operações interestaduais de entrada sujeitas ao fato gerador do ICMS.

É de suma importância ressaltar que na Estimativa Simplificado o contribuinte não terá direito a dedução, manutenção, estorno ou glosa de crédito, sendo que, salvo exceções, o recolhimento do imposto neste regime encerra a cadeia tributária. Outra característica deste regime é que, no caso de industrial mato-grossense em saídas internas, substitui-se o ICMS por Substituição Tributária e aplica-se a Estimativa Simplificado, observando a carga média a ser aplicada ao contribuinte adquirente.

Nos termos do Art. 87-J-6, $\S 1^{\circ}$, incisos I, II, III e IV do RICMS, este regime substitui os regimes Garantido, Garantido Integral, Substituição Tributária e Estimativa por Operação. Deste modo, mesmo para as mercadorias destinadas ao uso, consumo e ativo permanente do contribuinte, aplicar-se-á a carga média descrita no Anexo XVI do RICMS.

Outra peculiaridade deste regime é a exclusão da base de cálculo do imposto: 
O valor das operações com bens, mercadorias e respectivas prestações de serviço de transporte alcançados por imunidade;

D valor das operações contempladas com isenção do ICMS, concedida nos termos de convênio celebrado no âmbito do CONFAZ (Conselho Nacional de Políticas Fazendária);

O valor do imposto devido por substituição tributária, retido pelo remetente, destacado na nota fiscal que acobertar a operação;

O valor das operações e respectivas prestações de serviço de transporte:

- Remessa para industrialização;

- Remessa por conta e ordem;

- Devolução, remessa ou retorno para conserto;

- Substituição em garantia;

- Mercadorias remetidas para treinamento;

- Mercadorias destinadas à demonstração;

- Remessa em consignação mercantil, arrendamento leasing), empréstimo e locação, comodato e outras operações de natureza semelhante;

- Mercadorias destinadas a mostruário.

Em geral, a apuração do imposto no regime Estimativa Simplificado encerra a cadeia de tributação do ICMS. Entretanto, o RICMS prevê quatro hipóteses em que não haverá o encerramento da cadeia: transferência de estabelecimento de outro Estado, do mesmo titular; quando o MVA (margem de valor agregado) aplicado for superior a $1 \frac{1}{2}$ o disposto no anexo XV do RICMS; e quando detectado que o imposto foi recolhido a menor. Assim também, não haverá encerramento da cadeia em relação a operações com as seguintes mercadorias:

Armas e munições, suas partes e acessórios, classificados no capítulo 93 da NBM/SH ${ }^{5}$ (capítulo 93 da NCM/SH ${ }^{6}$ );

Embarcações de esporte e de recreação, classificadas no código 8903 da NBM/SH (código 89.03 da NCM);

\footnotetext{
${ }^{5}$ Nomenclatura Brasileira de Mercadoria - Sistema Harmonizado.

${ }^{6}$ Nomenclatura Comum do Mercosul - Sistema Harmonizado.
} 
$\checkmark$ Joias classificadas nos códigos 7113 a 7116 da NBM/SH (códigos 71.13 a 71.16 da $\mathrm{NCM} / \mathrm{SH})$;

$\checkmark$ Cosméticos e perfumes classificados nos códigos 3303, 3304, 3305 e 3307 da NBM/SH (códigos 3303.00, 33.04, 33.05, 33.07 da $\mathrm{NCM} / \mathrm{SH})$.

A superveniência do Decreto $n^{0} 392 / 2011$ fez com que os contribuintes fossem tacitamente enquadrados na Estimativa Simplificada e a carga média a ser aplicada seria de acordo com o CNAE principal. No entanto, os contribuintes não impedidos podem pedir a saída do regime, apurando o imposto, por sua vez, no regime Normal. Para isso, o contribuinte deve solicitar à Agência Fazendária (AGENFA) o pedido de exclusão da Estimativa até o dia 30 de novembro de cada ano, sendo que os efeitos aplicar-se-ão para fatos geradores que ocorrerão a partir de $1^{\circ}$ de janeiro do ano seguinte, conforme delineia o Art. 87-J-12 do RICMS:

\footnotetext{
“Art. 87-J-12 Ressalvado o disposto no $\S 6^{\circ}$ deste artigo, a permanência no regime de estimativa simplificado é opcional, sendo facultado ao contribuinte mato-grossense não enquadrado como substituto tributário requerer, expressamente, a sua exclusão à Secretaria de Estado de Fazenda, até o último dia útil do mês de novembro de cada ano [...]."
}

Nos termos do Art. 87-J-13, $\S 1^{\circ}$ do RICMS:

" $1^{\circ} \mathrm{O}$ imposto devido a título de regime de estimativa simplificado deverá
ser recolhido pelo contribuinte até o $20^{\circ}$ (vigésimo) dia do segundo mês
subsequente ao da entrada da mercadoria no território mato-grossense."

O dispositivo supracitado obriga o contribuinte a recolher o imposto até o dia 20 do mês subsequente a entrada da mercadoria no estado. Todavia, tal obrigação, além de descabida, pois o fato gerador (saída da mercadoria ou prestação do serviço) pode ainda não ter ocorrido, pode também causar danos ao fluxo de caixa da empresa.

Ademais, o contribuinte incluso neste regime não está desobrigado do cumprimento das obrigações acessórias, "inclusive emissão de documentos fiscais e escrituração fiscal, nem do recolhimento do imposto devido pelas operações e ou prestações não alcançadas por este regime”. (Art. 87-J-15 do RICMS). 


\title{
4.3. REGIME DE APURAÇÃO SIMPLES NACIONAL
}

O Simples Nacional, segundo Fantoni (2013):

\begin{abstract}
"[...] é um regime de tratamento diferenciado e favorecido a serem dispensados às microempresas e empresas de pequeno porto (EPP) no âmbito da União, Estados, Distrito Federal e Municípios. A diferenciação de tratamento decorre principalmente da apuração e recolhimento da maioria dos impostos e contribuições da União, do ICMS estadual e distrital e do ISS municipal e distrital. Dessa forma, o Simples Nacional tem a tendência a reduzir a burocracia e a carga tributária."
\end{abstract}

Destarte, o legislador mato-grossense, considerando que as ME e EPP possuem menor capacidade para arcar com a carga tributária, consignou no Art. 47 do Anexo VIII do RICMS uma redução da carga tributária para os optantes do Simples.

Cabe-se ressaltar que a Lei Complementar 123/06 (que instituiu as ME e EPP) considera como ME e EPP o empresário, pessoa jurídica, ou a ela equiparada que aufira no ano-calendário receita igual ou inferior a R\$360.000,00 e R\$3.600.000,00, respectivamente. No entanto, considerando as desigualdades existentes no país, a Lei permitiu que os estados estabelecessem sublimites para fins de aplicação dos benefícios do Simples na apuração e recolhimento ICMS. Desse modo, por meio do Decreto $\mathrm{n}^{\circ}$ 1.415 de 31/12/2012, adotou-se, em Mato Grosso, o sublimite de receita anual de R\$ 2.520.000,00, em 2013, para que o contribuinte goze do benefício.

Para a apuração do ICMS dos optantes pelo Simples, com a superveniência do Estimativa Simplificado, estes também passaram a apurar o ICMS pela carga média, todavia, considerando que aplicar-se-á, neste caso, a redução de carga tributária constante no Art. 47 do Anexo VIII do RICMS, conforme está escrito no Art. 87-J-7, inciso I do RICMS:

"I - contribuintes optantes pelo Regime Especial Unificado de Arrecadação de Tributos e Contribuições devidos pelas Microempresas e Empresas de Pequeno Porte - Simples Nacional, instituído pelo artigo 12 da Lei Complementar (nacional) $\mathrm{n}^{\circ} 123$, de 14 de dezembro de 2006: o percentual de carga média corresponderá ao definido em consonância com o disposto no artigo 47 do Anexo VIII deste regulamento." 
Desta forma, o contribuinte optante pelo Simples irá apurar e recolher o ICMS da seguinte forma: Carga Média do Simples $=($ Valor da NF) $x(\%$ do Art. 47 do anexo VIII do RICMS). Cabe-se ressaltar que o percentual corrente aplicado é de 7,5\%.

Todavia, mesmo que a carga média, segundo o regulamento, substitua o Garantido, Garantido Integral e Substituição Tributária, a SEFAZ vem entendendo que, no caso de produtos sujeitos a Substituição Tributária, os contribuintes optantes pelo Simples devem apurar e recolher o ICMS observando os percentuais do Anexo XVI, em detrimento do benefício da redução da carga tributária.

Já para as aquisições de bens e mercadoria destinados ao ativo permanente, uso e consumo, será devido para Mato Grosso o ICMS calculado na seguinte sistemática: Valor da NF x alíquota de 4\%. Tal procedimento se sustenta no que está consignado no Art. 47 do anexo VIII, inciso II do RICMS:

"II - 4,0\% (quatro inteiros por cento) do valor total da Nota Fiscal de aquisição em relação aos bens e mercadorias destinados à integração ao ativo permanente ou ao uso e consumo do estabelecimento, para os anos de 2010 a 2014."

\subsection{REGIME DIFERENCIAL DE ALÍQUOTA}

Segundo o Art. $3^{\circ}$ da Lei 7.098/98, o ICMS Diferencial de Alíquota se aplica:

\footnotetext{
"XIII - da entrada no estabelecimento de contribuinte de bem ou mercadoria, adquirida em outro Estado, destinada a uso, consumo ou ativo permanente; XIV - da utilização, por contribuinte, de serviço cuja prestação se tenha iniciado em outro Estado e não esteja vinculada a operação ou prestação subsequente, alcançada pela incidência do imposto;( Art. $3^{\circ}$ da Lei 7.098/98)."
}

Deste modo, temos consignado no artigo supra o fato gerador do ICMS. Para tanto, considera-se como base de cálculo o valor da prestação ou operação. Todavia, o ICMS Diferencial terá uma alíquota e uma sistemática de apuração para cada regime (Normal, Estimativa Simplificado e Simples), conforme demonstraremos a seguir.

\subsubsection{No Regime Normal}


Nesta sistemática, o ICMS Diferencial de Alíquota será apurado da seguinte forma:

Base de cálculo: valor da prestação ou operação;

Alíquota: diferença entre a alíquota interna aplicada em Mato Grosso e a alíquota aplicada no estado de origem

ICMS Diferencial devido: Base de cálculo x Alíquota.

\subsubsection{No Regime Estimativa Simplificado}

Conforme o RICMS, este regime substituiu o Garantido, de forma que, em linhas gerais, não há mais distinção entre bens e mercadorias destinadas a venda ou ao ativo permanente, uso ou consumo. Desta forma, aplicar-se-á, no caso de mercadorias destinadas ao ativo permanente, uso ou consumo a mesma sistemática das mercadorias destinadas à comercialização.

Então, para o cálculo do ICMS devido aos fatos geradores abrangidos pelo diferencial de alíquota, o contribuinte aplicará a sistemática do Estimativa Simplificado: ICMS devido: Valor da operação ou prestação x Carga Média (Anexo XVI).

\subsubsection{No Simples Nacional}

Conforme já observado, os contribuintes optantes pelo Simples apurarão o ICMS devido de acordo com o regime Estimativa Simplificado, inclusive no tocante aos bens e mercadorias destinados ao ativo permanente, uso e consumo, observando o benefício da redução da base de cálculo consignado no Art. 47 do anexo VIII do RICMS.

Destarte o artigo supra estabelece que o ICMS devido seja calculado da seguinte forma: ICMS devido: Valor da Operação ou prestação x Carga Tributária Reduzida (4\%, conforme inciso II, Art. 47 Anexo VIII do RICMS).

\section{CASO PRÁTICO SIMULADO}


O presente estudo de caso simulado pretende apurar e comparar o ICMS a pagar, nos diversos regimes, a saber:

1) Normal;

2) Estimativa Simplificado;

3) Simples;

4) Diferencial de Alíquota.

Para tanto, trata-se de uma empresa hipotética, sendo que essa empresa atua no ramo comercial com o CNAE: 4789-0/99: COMÉRCIO VAREJISTA DE OUTROS PRODUTOS NÃO ESPECIFICADOS ANTERIORMENTE.

De início, fora elaborado um Balanço Patrimonial comum a todos os regimes conforme mostra a Quadro 3 (apêndice). Então, partindo desses dados, foram simulados seis fatos, comuns a todos os regimes, para verificar como o ICMS incidiria em cada regime, bem como para apurar o seu valor a pagar (ver Quadros de 4 a 6, apêndice).

A partir de então, começou-se a distinguir como cada operação iria se comportar nos diversos regimes estudados. Assim sendo, elaborou-se uma tabela exemplificativa de incidência para cada regime de acordo com os seis fatos supracitados. Ressalta-se que para fins de estudo, as mercadorias compradas de fora do Estado de Mato Grosso são originadas do Estado de São Paulo e a margens de lucro aplicadas para venda são de $10 \%, 20 \%, 30 \%, 40 \%, 50 \%$ e $60 \%$ sobre o valor da compra das mercadorias respectivamente.

Na Figura 14 ver-se que com margem de lucro de $10 \%$, verifica-se que o Normal é mais benéfico para a empresa em relação ao método de Estimativa. No entanto, no Simples se apurou o menor ICMS a pagar, tanto com margem de $10 \%$ quanto nas demais margens subsequentes.

Figura 14 - Representação gráfica do ICMS a pagar com margem de lucro de 10\% 


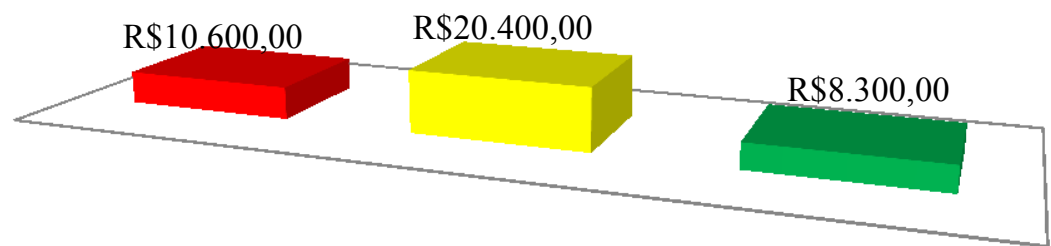

- REGIME DE APURAÇÃO NORMAL

REGIME DE APURAÇÃO ESTIMATIVA SIMPLIFICADA

- REGIME DE APURAÇÃO SIMPLES NACIONAL

Fonte: dados da pesquisa.

Os dados básicos que confirmam o resultado acima da Figura 14 estão devidamente apurados, demonstrados e consubstanciados no Apêndice mediante a Figura 3 - Balancete comparativo com margem de lucro: $10 \%$ e, na Figura 4 Demonstração simplificada do resultado.

Na Figura 15 tem-se a margem de lucro de 20\%, na qual o Regime Normal ainda prevalece em relação ao Regime de Estimativa. Podemos notar também que independente da margem de lucro adotada, o ICMS, Estimativa e Simples a pagar, não se altera, então, mantêm-se constante.

Figura 15 - Representação gráfica do ICMS a pagar com margem de lucro de $20 \%$

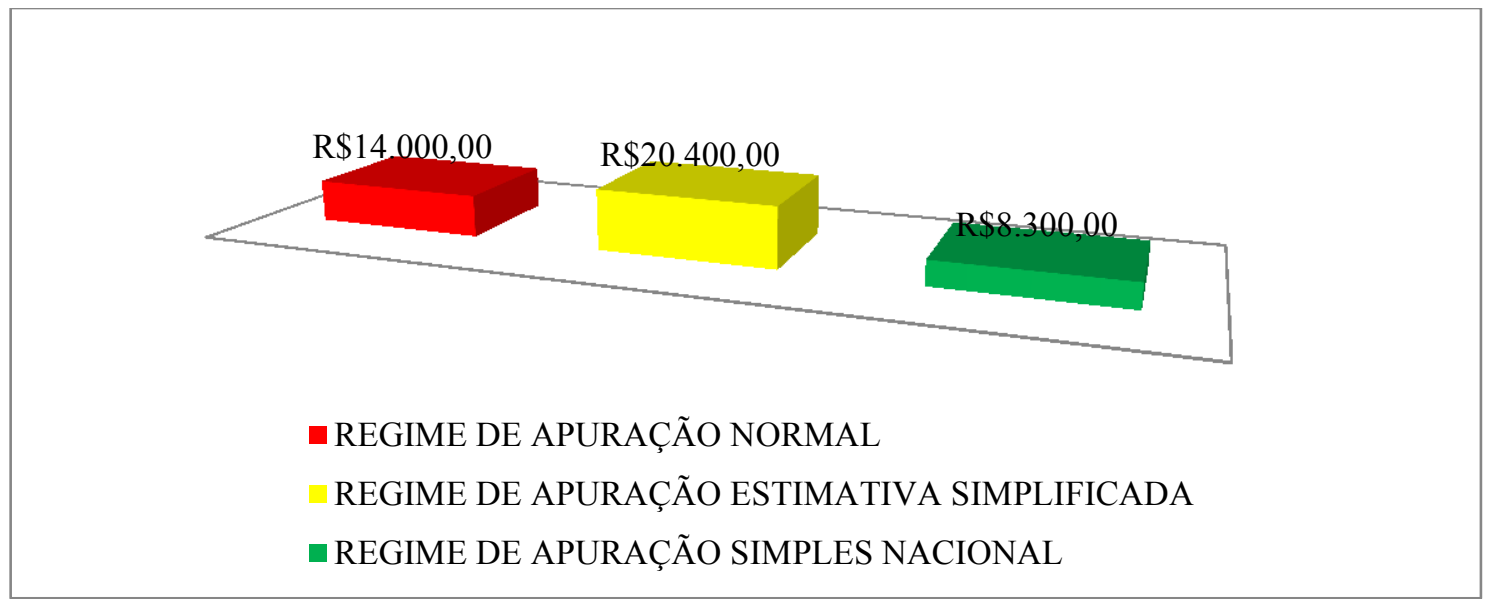

Fonte: dados da pesquisa.

Os dados básicos que confirmam o resultado acima da Figura 15 estão devidamente apurados, demonstrados e consubstanciados no Apêndice mediante a 
Figura 4 - Balancete comparativo com margem de lucro: $20 \%$ e, na Figura 5 Demonstração simplificada do resultado.

Já a 30\% (Figura 16) nota-se que os regimes, Normal e Estimativa, apresentam o ICMS a pagar bem semelhantes. Então, caso a empresa trabalhe nessa faixa de margem de lucro, faz-se necessário um estudo mais detalhado do melhor regime a ser adotado, pois, pequenas variações podem fazer com que um regime seja mais benéfico.

Figura 16 - Representação gráfica do ICMS a pagar com margem de lucro de 30\%

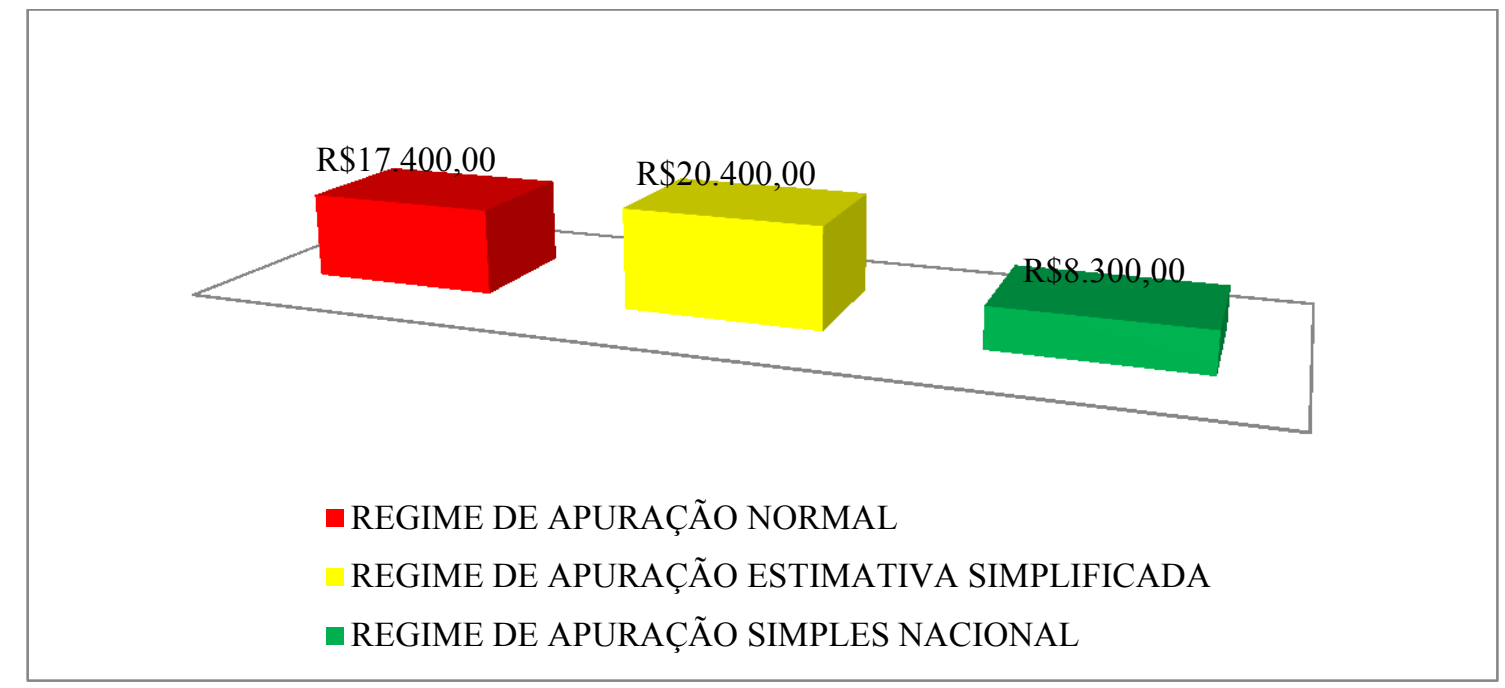

Fonte: dados da pesquisa.

Os dados básicos que confirmam o resultado acima da Figura 16 estão devidamente apurados, demonstrados e consubstanciados no Apêndice mediante a Figura 6 - Balancete comparativo com margem de lucro: $30 \%$ e, na Figura 7 Demonstração simplificada do resultado.

Com margem de 40\% (Figura 17), o regime, Estimativa já se torna mais benéfico para a empresa. Nota-se que enquanto no Normal o ICMS a pagar aumenta proporcionalmente ao aumento da margem de lucro, nos regimes, Estimativa e Simples, o imposto a recolher é constante. Então, caso a empresa opere com qualquer margem de lucro superior a $38,82 \%$ o Estimativa será mais benéfico.

Figura 17 - Representação gráfica do ICMS a pagar com margem de lucro de 40\% 


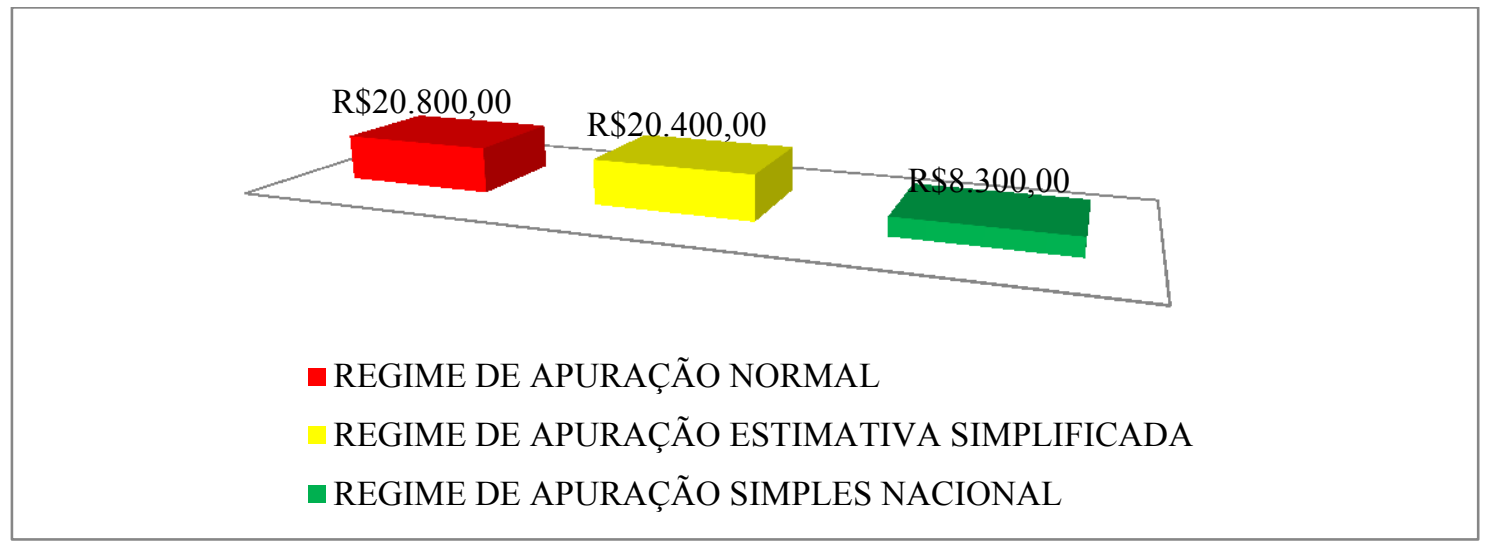

Fonte: dados da pesquisa.

Os dados básicos que confirmam o resultado acima da Figura 17 estão devidamente apurados, demonstrados e consubstanciados no Apêndice mediante a Figura 8 - Balancete comparativo com margem de lucro: $40 \%$ e, na Figura 9 Demonstração simplificada do resultado.

Com margem de 50\% (Figura 18), o regime, Estimativa já se torna mais benéfico para a empresa. Nota-se que enquanto no Normal o ICMS a pagar aumenta proporcionalmente ao aumento da margem de lucro, nos regimes, Estimativa e Simples, o imposto a recolher é constante. Então, caso a empresa opere com qualquer margem de lucro superior a $38,82 \%$ o Estimativa será mais benéfico.

Figura 19 - Representação gráfica do ICMS a pagar com margem de lucro de $60 \%$

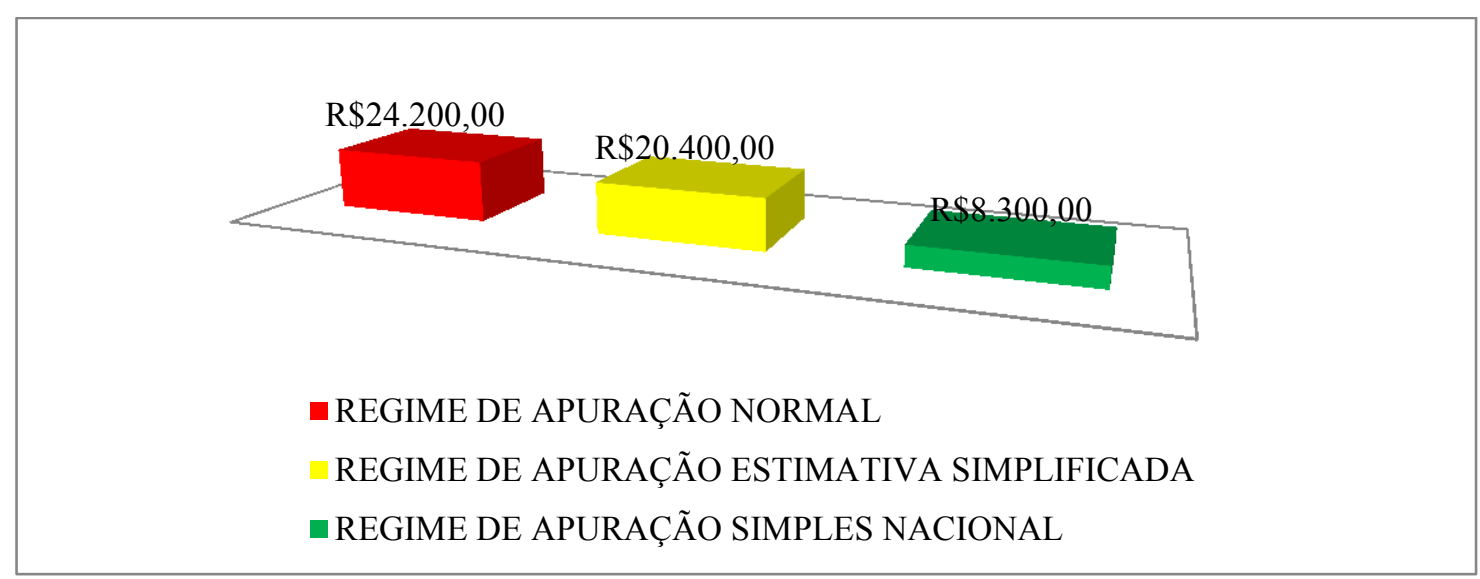

Fonte: dados da pesquisa.

Os dados básicos que confirmam o resultado acima da Figura 18 estão devidamente apurados, demonstrados e consubstanciados no Apêndice mediante a 
Figura 10 - Balancete comparativo com margem de lucro: 50\% e, na Figura 11 Demonstração simplificada do resultado.

Com margem de 60\% (Figura 20), o regime, Estimativa já se torna mais benéfico para a empresa. Nota-se que enquanto no Normal o ICMS a pagar aumenta proporcionalmente ao aumento da margem de lucro, nos regimes, Estimativa e Simples, o imposto a recolher é constante. Então, caso a empresa opere com qualquer margem de lucro superior a $38,82 \%$ o Estimativa será mais benéfico.

Figura 20 - Representação gráfica do ICMS a pagar com margem de lucro de $60 \%$

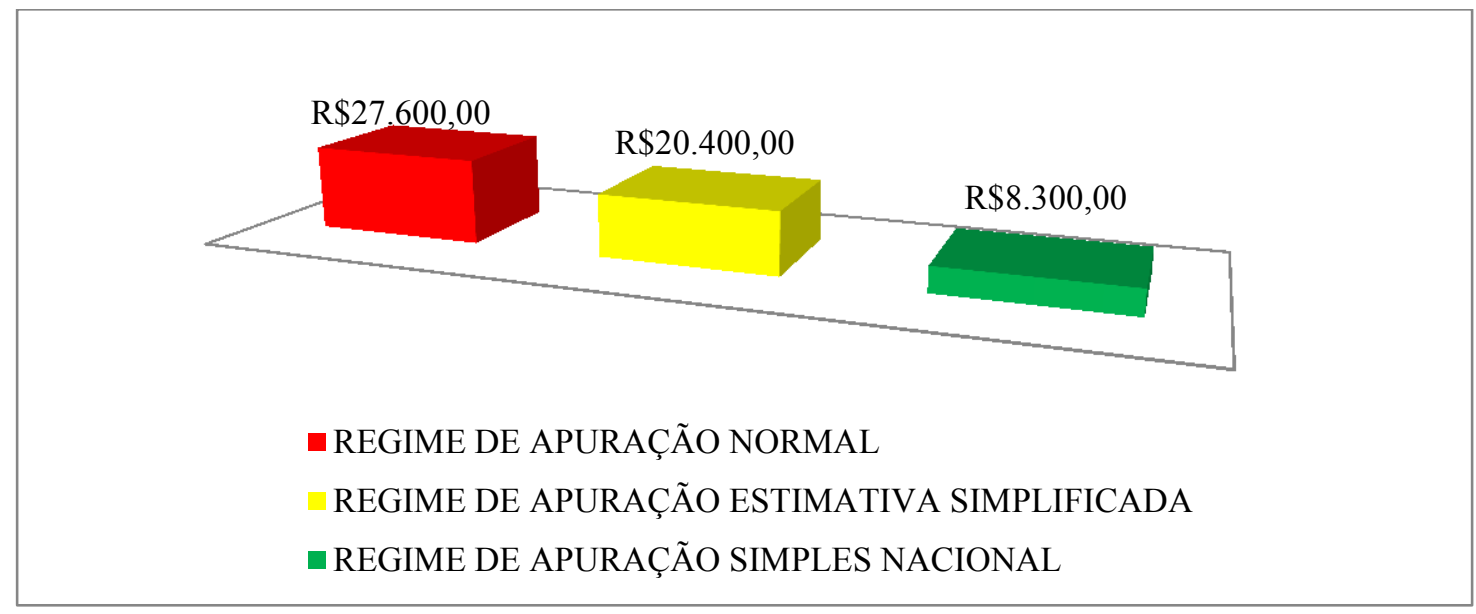

Fonte: dados da pesquisa.

Os dados básicos que confirmam o resultado acima da Figura 19 estão devidamente apurados, demonstrados e consubstanciados no Apêndice mediante a Figura 12 - Balancete comparativo com margem de lucro: 60\% e, na Figura 13 Demonstração simplificada do resultado.

\section{CONSIDERAÇÕES FINAIS}

O objetivo deste trabalho prático-científico foi o objetivo de apresentar e comparar tecnicamente os diversos regimes de apuração do ICMS no Estado de Mato Grosso, em especial os Regimes: Normal, Estimativa Simplificado, Simples e Diferencial de Alíquota. Assim, a partir de uma pesquisa descritiva e bibliográfica, principalmente remetendo-se à legislação, pretende-se analisar o ICMS através do 
tempo até 2013 (alteração mais recente), buscando-se compreender a sua sistemática e suas diversas formas de apuração.

Diante do dos resultados simulados, notamos que o melhor regime a ser adotado por uma empresa dependerá da margem de lucro que ela opera em seu negócio. Assim, comparando os regimes Normal e Simplificado, inferimos que quanto menor a margem de lucro, mais benéfico será ao contribuinte optar pelo Regime de apuração Normal. Desse modo, se a empresa operar com margem pouco menor de $40 \%$, mais exatamente $38,82 \%$, compensará a ela optar pelo Normal. Já se ela operar com margem superior, o Simplificado será mais interessante.

Outro ponto concludente deste trabalho foi que caso a empresa opte pelo Simplificado ou Simples, independentemente da sua margem de lucro utilizada, o imposto a ser pago será o mesmo. Isto posto, tal sistemática beneficia as empresas com maior margem de valor agregado, geralmente que comercializam produtos de luxo, em detrimento dos negócios que vendem produtos com menor margem, infringindo, assim, o princípio da capacidade contributiva do contribuinte.

Constata-se que na sistemática de tributação Simplificado e Simples levar em consideração para apuração do ICMS a pagar apenas o CNAE do contribuinte e o valor da entrada da operação ou prestação, este regime cria distorções na cobrança do imposto. Sabemos que as empresas de maior porte conseguem comprar suas mercadorias a um menor preço, ou seja, a base de cálculo para a apuração do imposto e consequentemente o imposto a pagar de uma grande empresa será menor do que de uma pequena empresa, mesmo em se tratando do mesmo produto.

Contudo, entre os regimes Normal, Estimativa Simplificado e Simples, o último se mostrou mais vantajoso em relação aos outros, embora, a CNI - Confederação Nacional da Industria, em estudo recente publicado na Folha de São Paulo, constatou que o Estado de Mato Grosso para os contribuintes do Simples Nacional é "o campeão em peso de impostos, o desembolso do empresário chega a $8,6 \%$ de sua receita total". Assim, se o custo Brasil inviabiliza muitos negócios, o "custo Mato Grosso", consequentemente, inviabiliza muito mais a livre iniciativa do que em outros Estados. Além disso, geralmente os produtos supérfluos possuem um maior valor agregado do que os produtos essenciais. Como nesse regime se leva em conta apenas o CNAE do contribuinte, vai de encontro à seletividade do ICMS, conforme está consignado na CF. 
Ademais, abre-se um leque para que os contabilistas ofereçam aos seus clientes um planejamento tributário minucioso para que se opte pelo regime fiscal mais benéfico. Embora a denominação "simples" e seus derivados geralmente facilitam a apuração do imposto a ser pago, conforme observado, quando o contribuinte utiliza uma margem de lucro baixa, essas sistemáticas geram um imposto a pagar à maior do que o efetivamente poderia ser apurado caso o contribuinte optasse pelo regime "normal" de tributação.

\section{REFERÊNCIAS}

AFONSO, J. R. Arrecadação de ICMS foi recorde em 2012: R\$ 330 bilhões. Estudo encomendado pela FGV e Disponível em: http://oglobo.globo.com/economia/arrecadacaode-icms-foi-recorde-em-2012-330-bilhoes-7502356. Acessado em: 23/11/2013.

ATALIBA, G. Hipótese de Incidência Tributária. São Paulo, Malheiros Editores: 1992.

BANCO CENTRAL DO BRASIL (BCB). Arrecadação do ICMS por região em 2008. Estudo Disponível em: http://www.bcb.gov.br/pec/boletimregional/port/2009/04/br200904b3p.pdf. Acessado em: $02 / 11 / 2013$.

BORBA, C. Direito Tributário. Rio de Janeiro: Elsevir Editora, 2014.

BRASIL. Constituição da República Federativa do BRASIL DE 1988. Disponível em: http://www.planalto.gov.br/ccivil_03/ constituicao/constituicao. Acessado em: $16 / 09 / 2013$.

BRASIL, Lei Complementar n. 123, 14 de dezembro de 2006. Dispões sobre o SIMPLES NACIONAL. Disponível

em:

http://www.receita.fazenda.gov.br/Legislacao/Leis Complementares/2006/leicp123.htm. Acessado em: 16/09/2013. 
BRASIL. Anexos do RICMS/MT. Disponível em: http://sefaz.mt.gov.br. Acessado em 16/09/2013.

BRASIL. Convênios. Disponível em: http://www.planalto.gov.br/ccivil_03/leis/lcp/lcp24.htm Acessado em: 16/09/2013.

BRASIL. Lei Kandir. Disponível em: http://www.planalto.gov.br/ccivil_03/leis/lcp/ lcp87.htm. Acessado em: 16/09/2013.

BRASIL. Lei n. 7.098/98. Consolida normas referentes ao Imposto sobre Operações relativas à Circulação de Mercadorias e sobre Prestações de Serviços de Transporte Interestadual e Intermunicipal e de Comunicação em Mato Grosso - ICMS. Disponível em: http://sefaz.mt.gov.br. Acessado em 16/09/2013.

BRASIL. RICMS / MT - DECRETO $\mathbf{N}^{\circ}$ 1.944, DE 06.10.1989. Dispõe sobre o Regulamento do ICMS no Estado de Mato Grosso. Disponível em: http://sefaz.mt.gov.br. Acessado em 16/09/2013.

CARVALHO, P. B. Curso de direito tributário. São Paulo: Saraiva, 1995.

CNI. Estudo da Confederação Nacional da Indústria. Dispõe sobre a carga tributária das empresas optantes pelo Simples. Disponível em: http://www1.folha.uol.com.br/mercado /2013/09/1344606-parana-oferece-menor-cargatributaria-a-micro-e-pequenas-empresas-aponta-cni.shtml. Acessado em: 20/10/2013.

FANTONI, A. F. Legislação Tributária do Estado de Mato Grosso - comentada. Cuiabá, Apostila: 2013.

MAGGI, B. Ou vamos à criação de um Fundo Constitucional, ou vamos à guerra fiscal, estamos preparados para as duas coisas em Mato Grosso. Disponível em: http://blairomaggi.com.br/noticia/vamos-a-criacao-de-um-fundo-ou-a-guerra-fiscal- 
estamos-preparados-para-as-duas-coisas-disse-blairo-ao-defender-incentivos-em-mt. Acessado em: 15/11/2013.

MENDES, G. F. Curso de Direito Constitucional. São Paulo: Saraiva, 2007.

REZENDE, F. R. ICMS: Gênese, Mutações, Atualidade e Caminhos Para a Recuperação. Brasília: FGV Projetos, 2012. 


\section{APÊNDICE}

Quadro 3 - Balanço patrimonial simulado

\begin{tabular}{|c|c|c|c|}
\hline \multicolumn{4}{|c|}{ BALANÇO PATRIMONIAL EM 31/12/2012 } \\
\hline \multicolumn{2}{|c|}{ ATIVO } & \multicolumn{2}{|c|}{ PASSIVO } \\
\hline CIRCULANTE & $200.000,00$ & CIRCULANTE & 0,00 \\
\hline DISPONÍVEL & $200.000,00$ & OBRIGAÇÕES & 0,00 \\
\hline Banco Conta Movimento & $200.000,00$ & Fornecedores & \\
\hline CRÉDITOS & 0,00 & ICMS a Pagar & \\
\hline ICMS a Recuperar CP & & NÃO CIRCULANTE & \\
\hline ESTOQUES & 0,00 & PATRIMÔNIO LÍQUIDO & $200.000,00$ \\
\hline Mercadorias & & CAPITAL SOCIAL & $200.000,00$ \\
\hline NÃO CIRCULANTE & 0,00 & Capital Social Realizado & $200.000,00$ \\
\hline REALIZÁVEL A LONGO PRAZO & 0,00 & & \\
\hline ICMS a Recuperar LP & & & \\
\hline IMOBILIZADO & 0,00 & & \\
\hline Móveis e Utensílios & & & \\
\hline ATIVO TOTAL & $200.000,00$ & PASSIVO TOTAL & $200.000,00$ \\
\hline
\end{tabular}

Fonte: dados da pesquisa.

Volume 5, Número 10

Jul./Dez. 2016
Revista UNEMAT de Contabilidade

ISSN: 2316-8072 
Quadro 4 - Regime de apuração normal

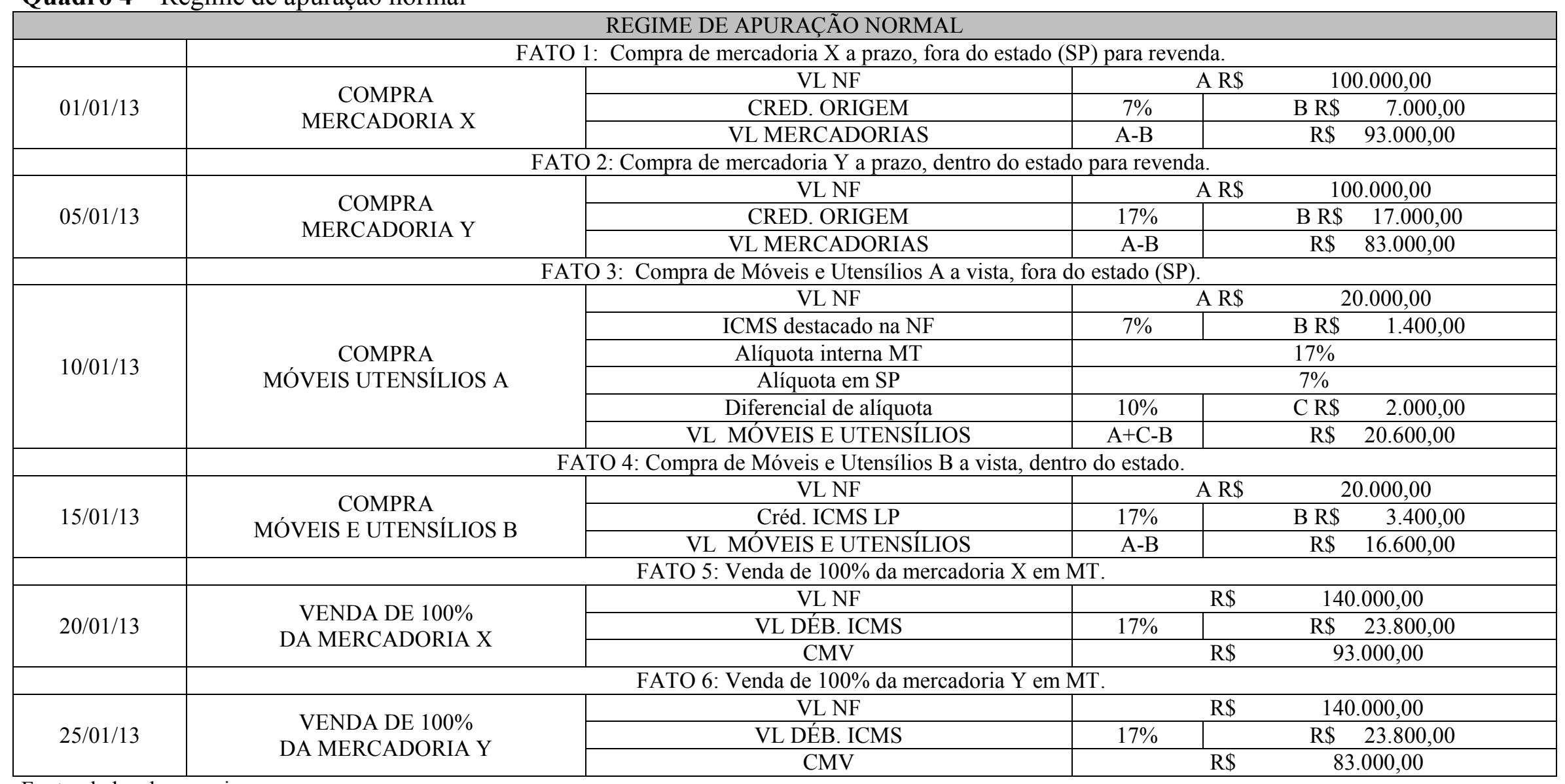

Fonte: dados da pesquisa.

Volume 5, Número 10

Jul./Dez. 2016
Revista UNEMAT de Contabilidade

ISSN: 2316-8072 
Quadro 5 - Regime de apuração estimativa simplificada

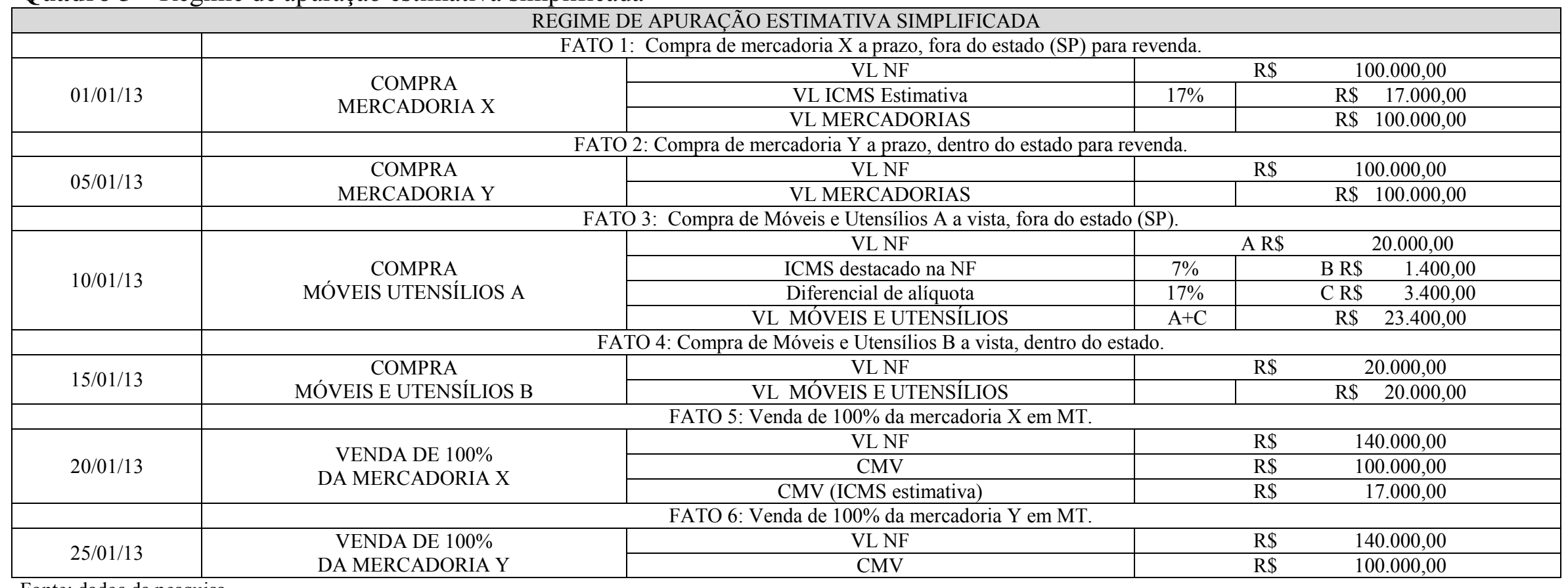

Fonte: dados da pesquisa.

Volume 5, Número 10

Jul./Dez. 2016
Revista UNEMAT de Contabilidade

ISSN: 2316-8072 
Quadro 6 - Regime de apuração simples nacional

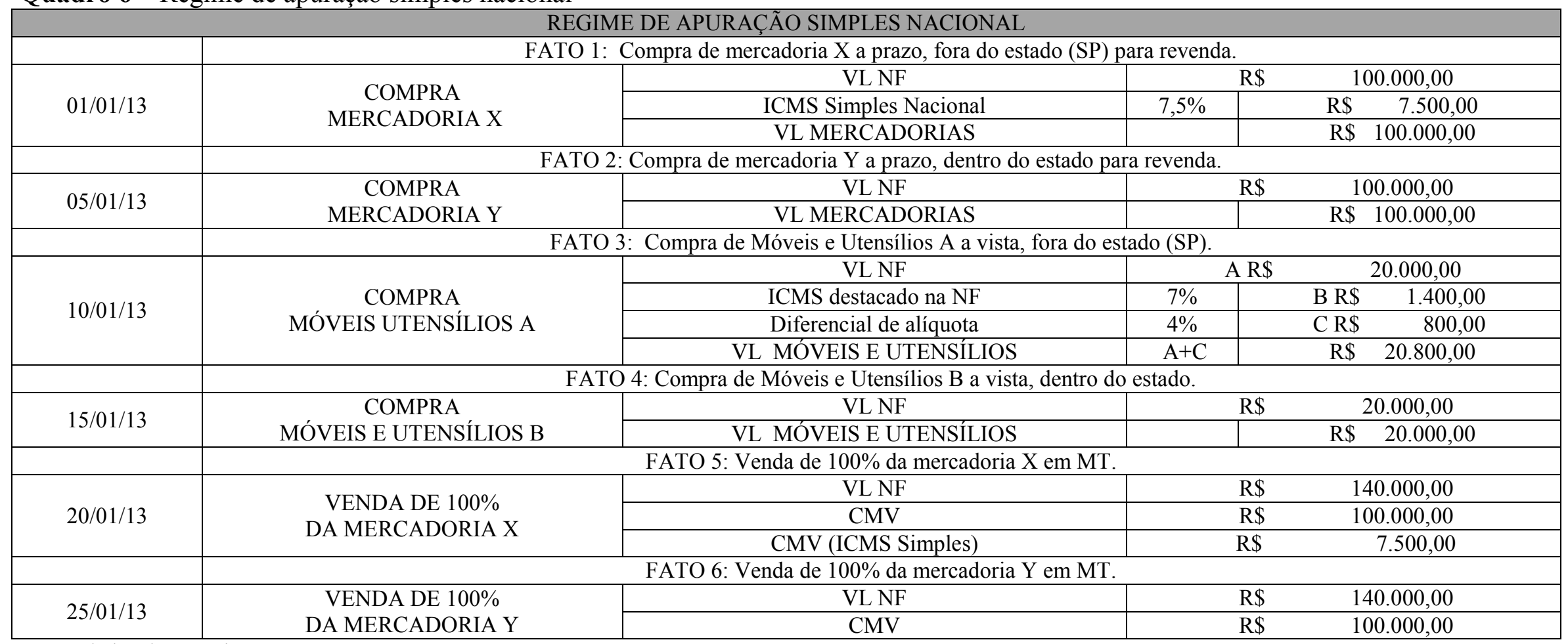

Fonte: dados da pesquisa.

Volume 5, Número 10

Jul./Dez. 2016
Revista UNEMAT de Contabilidade

ISSN: 2316-8072 
Figura 3 - Balancete comparativo com margem de lucro: 10\%

\begin{tabular}{|c|c|c|c|c|c|c|}
\hline \multicolumn{7}{|c|}{ BALANCETE COMPARATIVO COM MARGEM DE L } \\
\hline \multirow{4}{*}{ CONTA } & \multicolumn{6}{|c|}{ REGIMES DE APURAÇÃO } \\
\hline & \multicolumn{2}{|c|}{ NORMAL } & \multicolumn{2}{|c|}{ SIMPLIFICADA } & \multicolumn{2}{|c|}{ SIMPLES } \\
\hline & \multicolumn{2}{|c|}{ SALDOS } & \multicolumn{2}{|c|}{ SALDOS } & \multicolumn{2}{|c|}{ SALDOS } \\
\hline & DEVEDOR & CREDOR & DEVEDOR & CREDOR & DEVEDOR & CREDOR \\
\hline Banco c/ Movimento & R\$ $380.000,00$ & & R\$ 380.000,00 & & R\$ 380.000,00 & \\
\hline Móveis e Utensílios & RS $37.200,00$ & & R\$ $43.400,00$ & & R\$ $40.800,00$ & \\
\hline Fornecedores & & R\$ 200.000,00 & & R\$ 200.000,00 & & $\mathrm{R} \$ \mathbf{2 0 0 . 0 0 0 , 0 0}$ \\
\hline ICMS a Pagar & & R\$ $10.600,00$ & & R\$ $20.400,00$ & & R\$ $\quad 8.300,00$ \\
\hline Capital Social Realizado & & $\mathrm{R} \$ 200.000,00$ & & $\mathrm{R} \$ 200.000,00$ & & $\mathrm{R} \$ 200.000,00$ \\
\hline Venda de Mercadoria & & $\mathrm{R} \$ 220.000,00$ & & $\mathrm{R} \$ 220.000,00$ & & $\mathrm{R} \$ 220.000,00$ \\
\hline Despesa com ICMS & R\$ $37.400,00$ & & - & - & - & - \\
\hline CMV & $\mathrm{R} \$ 176.000,00$ & & $\mathrm{R} \$ 217.000,00$ & & $\mathrm{R} \$ 207.500,00$ & \\
\hline TOTAL & R\$ $630.600,00$ & R\$ $630.600,00$ & R\$ $640.400,00$ & R\$ 640.400,00 & $\mathrm{R} \$ 628.300,00$ & R\$ 628.300,00 \\
\hline
\end{tabular}

Fonte: dados da pesquisa.

Figura 4 - Demonstração simplificada do resultado

\begin{tabular}{|c|c|c|c|c|c|c|}
\hline \multicolumn{7}{|c|}{ DEMONSTRASÃ̃O SIMPLIFICADA DO RESULTADO } \\
\hline \multirow{2}{*}{ CONTA } & \multicolumn{6}{|c|}{ REGIMES DE APURA Ç்̃̃ } \\
\hline & \multicolumn{2}{|c|}{ NORMAL } & \multicolumn{2}{|c|}{ SIMPLIFICADA } & \multicolumn{2}{|c|}{ SIMPLES } \\
\hline Vendas & $\mathrm{RS}$ & $220.000,00$ & RS & 220.000,00 & RS & 220.000,00 \\
\hline (-) ICMS s/Vendas & $\mathrm{RS}$ & $37.400,00$ & $\mathrm{RS}$ & $17.000,00$ & R\$ & $7.500,00$ \\
\hline$(-)$ CMV & R\$ & $176.000,00$ & RS & $200.000,00$ & RS & $200.000,00$ \\
\hline (=) Lucro Bruto & $\mathrm{R} \$$ & $6.600,00$ & $\mathrm{RS}$ & $3.000,00$ & $\mathrm{RS}$ & $12.500,00$ \\
\hline (=) Lucro Bruto / Vendas & & $3,00 \%$ & & $1,36 \%$ & & $5,68 \%$ \\
\hline
\end{tabular}

Fonte: dados da pesquisa. 
Figura 5 - Balancete comparativo com margem de lucro: 20\%

\begin{tabular}{|c|c|c|c|c|c|c|}
\hline \multicolumn{7}{|c|}{ BALANCETE COMPARATIVO COM MARGEM DE LUCRO: 20\% } \\
\hline \multirow{4}{*}{ CONTA } & \multicolumn{6}{|c|}{ REGIMES DE APURAÇÃO } \\
\hline & \multicolumn{2}{|c|}{ NORMAL } & \multicolumn{2}{|c|}{ SIMPLIFICADA } & \multicolumn{2}{|c|}{ SIMPLES } \\
\hline & \multicolumn{2}{|c|}{ SALDOS } & \multicolumn{2}{|c|}{ SALDOS } & \multicolumn{2}{|c|}{ SALDOS } \\
\hline & DEVEDOR & CREDOR & DEVEDOR & CREDOR & DEVEDOR & CREDOR \\
\hline Banco c/ Movimento & $\mathrm{R} \$ \mathbf{4 0 0 . 0 0 0 , 0 0}$ & & $\mathrm{R} \$ 400.000,00$ & & $\mathrm{R} \$ \mathbf{4 0 0 . 0 0 0 , 0 0}$ & \\
\hline Móveis e Utensílios & $\mathrm{R} \$ \mathbf{3} \quad 37.200,00$ & & $\mathrm{R} \$ \mathrm{~T} \quad 43.400,00$ & & $\mathrm{R} \$ \mathrm{~T}^{2} \mathrm{40.800,00}$ & \\
\hline Fornecedores & & $\mathrm{R} \$ 200.000,00$ & & $\mathrm{R} \$ 200.000,00$ & & $\mathrm{R} \$ 200.000,00$ \\
\hline ICMS a Pagar & & $\mathrm{R} \$ \quad 14.000,00$ & & R\$ $20.400,00$ & & $\mathrm{R} \$ \mathbf{8 . 3 0 0 , 0 C}$ \\
\hline Capital Social Realizado & & $\mathrm{R} \$ 200.000,00$ & & $\mathrm{R} \$ 200.000,00$ & & $\mathrm{R} \$ 200.000,00$ \\
\hline Venda de Mercadoria & & $\mathrm{R} \$ 240.000,00$ & & $\mathrm{R} \$ 240.000,00$ & & $\mathrm{R} \$ 240.000,00$ \\
\hline Despesa com ICMS & R\$ $40.800,00$ & & - & - & - & - \\
\hline CMV & $\mathrm{R} \$ 176.000,00$ & & $\mathrm{R} \$ 217.000,00$ & & $\mathrm{R} \$ 207.500,00$ & \\
\hline TOTAL & $\mathrm{R} \$ \mathbf{6 5 4 . 0 0 0 , 0 0}$ & $\mathrm{R} \$ 654.000,00$ & $\mathrm{R} \$ \mathbf{6 6 0 . 4 0 0 , 0 0}$ & $\mathrm{R} \$ 660.400,00$ & $\mathrm{R} \$ \mathbf{6 4 8 . 3 0 0 , 0 0}$ & $\mathrm{R} \$ 648.300,00$ \\
\hline
\end{tabular}

Fonte: dados da pesquisa.

Figura 6 - Demonstração simplificada do resultado

\begin{tabular}{|c|c|c|c|c|c|c|}
\hline \multirow{2}{*}{ CONTA } & \multicolumn{6}{|c|}{ REGIMES DE APURA GÃO } \\
\hline & \multicolumn{2}{|c|}{ NORMAL } & \multicolumn{2}{|c|}{ SIMPLIFICADA } & \multicolumn{2}{|c|}{ SIMPLES } \\
\hline Vendas & $\mathrm{RS}$ & 240.000,00 & $\mathrm{RS}$ & $240.000,00$ & $\mathbf{R} \$$ & $240.000,00$ \\
\hline (-) ICMS s/Vendas & RS & $40.800,00$ & $\mathrm{RS}$ & $17.000,00$ & $\mathrm{RS}$ & $7.500,00$ \\
\hline$(-)$ CMV & $\mathrm{RS}$ & $176.000,00$ & $\mathrm{RS}$ & $200.000,00$ & $\mathrm{R} \$$ & $200.000,00$ \\
\hline (=) Lucro Bruto & RS & $23.200,00$ & R\$ & $23.000,00$ & $\mathrm{R} \$$ & $32.500,00$ \\
\hline (=) Lucro Bruto / Vendas & & $9,67 \%$ & & $9,58 \%$ & & $13,54 \%$ \\
\hline
\end{tabular}
Fonte: dados da pesquisa. 
Figura 7 - Balancete comparativo com margem de lucro: 20\%

\begin{tabular}{|c|c|c|c|c|c|c|}
\hline \multicolumn{7}{|c|}{ BALANCETE COMPARATIVO COM MARGEM DE LUCRO: 30\% } \\
\hline \multirow{4}{*}{ CONTA } & \multicolumn{6}{|c|}{ REGIMES DE APURAÇÃO } \\
\hline & \multicolumn{2}{|c|}{ NORMAL } & \multicolumn{2}{|c|}{ SIMPLIFICADA } & \multicolumn{2}{|c|}{ SIMPLES } \\
\hline & \multicolumn{2}{|c|}{ SALDOS } & \multicolumn{2}{|c|}{ SALDOS } & \multicolumn{2}{|c|}{ SALDOS } \\
\hline & DEVEDOR & CREDOR & DEVEDOR & CREDOR & DEVEDOR & CREDOR \\
\hline Banco c/ Movimento & $\mathrm{R} \$ \mathbf{4 2 0 . 0 0 0 , 0 0}$ & & $\mathrm{R} \$ 420.000,00$ & & $\mathrm{R} \$ \$$ 420.000,00 & \\
\hline Móveis e Utensílios & $\mathrm{R} \$ \quad 37.200,00$ & & $\mathrm{R} \$ \quad 43.400,00$ & & $\mathrm{R} \$ \quad 40.800,00$ & \\
\hline Fornecedores & & $\mathrm{R} \$ 200.000,00$ & & $\mathrm{R} \$ 200.000,00$ & & $\mathrm{R} \$ 200.000,00$ \\
\hline ICMS a Pagar & & $\mathrm{R} \$ \mathbf{1 7 . 4 0 0 , 0 0}$ & & $\mathrm{R} \$ \mathbf{2 0 . 4 0 0 , 0 0}$ & & $\mathrm{R} \$ \mathbf{8 . 3 0 0 , 0 0}$ \\
\hline Capital Social Realizado & & $\mathrm{R} \$ \mathbf{2 0 0 . 0 0 0 , 0 0}$ & & $\mathrm{R} \$ 200.000,00$ & & $\mathrm{R} \$ 200.000,00$ \\
\hline Venda de Mercadoria & & $\mathrm{R} \$ 260.000,00$ & & $\mathrm{R} \$ 260.000,00$ & & $\mathrm{R} \$ 260.000,00$ \\
\hline Despesa com ICMS & $\mathrm{R} \$ \quad 44.200,00$ & & - & - & - & - \\
\hline CMV & $\mathrm{R} \$ \mathbf{1 7 6 . 0 0 0 , 0 0}$ & & $\mathrm{R} \$ \mathbf{2 1 7 . 0 0 0 , 0 0}$ & & $\mathrm{R} \$ \mathbf{2 0 7 . 5 0 0 , 0 0}$ & \\
\hline TOTAL & $\mathrm{R} \$ \mathbf{6 7 7 . 4 0 0 , 0 0}$ & $\mathrm{R} \$ 677.400,00$ & $\mathrm{R} \$ \mathbf{6 8 0 . 4 0 0 , 0 0}$ & $\mathrm{R} \$ \mathbf{6 8 0 . 4 0 0 , 0 0}$ & $\mathrm{R} \$ 668.300,00$ & $\mathrm{R} \$ 668.300,00$ \\
\hline
\end{tabular}

Fonte: dados da pesquisa.

Figura 8 - Demonstração simplificada do resultado

\begin{tabular}{|c|c|c|c|c|c|c|}
\hline \multirow{2}{*}{ CONTA } & \multicolumn{6}{|c|}{ REGIMES DE APURA G̃̃̃O } \\
\hline & \multicolumn{2}{|c|}{ NORMAL } & \multicolumn{2}{|c|}{ SIMPLIFICADA } & \multicolumn{2}{|c|}{ SIMPLES } \\
\hline Vendas & $\mathrm{R} \$$ & 260.000,00 & $\mathrm{RS}$ & 260.000,00 & R\$ & 260.000,00 \\
\hline (-) ICMS s/Vendas & $\mathrm{R} \$$ & $44.200,00$ & $\mathrm{RS}$ & $17.000,00$ & $\mathrm{R} \$$ & $7.500,00$ \\
\hline$(-)$ CMV & $\mathrm{RS}$ & $176.000,00$ & RS & $200.000,00$ & $\mathrm{RS}$ & $200.000,00$ \\
\hline$(=)$ Lucro Bruto & $\mathrm{RS}$ & $39.800,00$ & $\mathrm{RS}$ & $43.000,00$ & $\mathrm{R} \$$ & $52.500,00$ \\
\hline$(=)$ Lucro Bruto / Vendas & & $15,31 \%$ & & $16,54 \%$ & & $20,19 \%$ \\
\hline
\end{tabular}

Fonte: dados da pesquisa. 
Figura 9 - Balancete comparativo com margem de lucro: 40\%

\begin{tabular}{|c|c|c|c|c|c|c|}
\hline \multicolumn{7}{|c|}{ BALANCETE COMPARATIVO COM MARGEM DE LUCRO: $\mathbf{4 0 \%}$} \\
\hline \multirow{4}{*}{ CONTA } & \multicolumn{6}{|c|}{ REGIMES DE APURAÇÃO } \\
\hline & \multicolumn{2}{|c|}{ NORMAL } & \multicolumn{2}{|c|}{ SIMPLIFICADA } & \multicolumn{2}{|c|}{ SIMPLES } \\
\hline & \multicolumn{2}{|c|}{ SALDOS } & \multicolumn{2}{|c|}{ SALDOS } & \multicolumn{2}{|c|}{ SALDOS } \\
\hline & DEVEDOR & CREDOR & DEVEDOR & CREDOR & DEVEDOR & CREDOR \\
\hline Banco c/ Movimento & $\mathrm{R} \$ 440.000,00$ & & $\mathrm{R} \$ 440.000,00$ & & $\mathrm{R} \$ 440.000,00$ & \\
\hline Móveis e Utensílios & $\mathrm{R} \$ 37.200,00$ & & $\mathrm{R} \$ \mathbf{4} \quad 43.400,00$ & & $\mathrm{R} \$ 40.800,00$ & \\
\hline Fornecedores & & $\mathrm{R} \$ 200.000,00$ & & $\mathrm{R} \$ 200.000,00$ & & $\mathrm{R} \$ 200.000,00$ \\
\hline ICMS a Pagar & & $\mathrm{R} \$ \mathbf{2 0 . 8 0 0 , 0 0}$ & & R\$ $20.400,00$ & & R\$ $\quad 8.300,00$ \\
\hline Capital Social Realizado & & $\mathrm{R} \$ 200.000,00$ & & $\mathrm{R} \$ 200.000,00$ & & $\mathrm{R} \$ \mathbf{2 0 0 . 0 0 0 , 0 0}$ \\
\hline Venda de Mercadoria & & $\mathrm{R} \$ 280.000,00$ & & $\mathrm{R} \$ 280.000,00$ & & $\mathrm{R} \$ \$ 280.000,00$ \\
\hline Despesa com ICMS & $\mathrm{R} \$ \quad 47.600,00$ & & - & - & - & - \\
\hline CMV & $\mathrm{R} \$ 176.000,00$ & & $\mathrm{R} \$ 217.000,00$ & & $\mathrm{R} \$ 207.500,00$ & \\
\hline TOTAL & $\mathrm{R} \$ 700.800,00$ & R\$ 700.800,00 & $\mathrm{R} \$ 700.400,00$ & $\mathrm{R} \$ \mathbf{7 0 0 . 4 0 0 , 0 0}$ & $\mathrm{R} \$ 688.300,00$ & R\$ 688.300,00 \\
\hline
\end{tabular}

Fonte: dados da pesquisa.

Figura 10 - Demonstração simplificada do resultado

\begin{tabular}{|c|c|c|c|c|c|c|}
\hline \multirow{2}{*}{ CONTA } & \multicolumn{6}{|c|}{ REGIMES DE APURAGÃO } \\
\hline & \multicolumn{2}{|c|}{ NORMAL } & \multicolumn{2}{|c|}{ SIMPLIFICADA } & \multicolumn{2}{|c|}{ SIMPLES } \\
\hline Vendas & $\mathrm{RS}$ & $280.000,00$ & $\mathrm{RS}$ & $280.000,00$ & $\mathrm{R} \$$ & $280.000,00$ \\
\hline (-) ICMS s/Vendas & $\mathrm{R} \$$ & $47.600,00$ & $\mathrm{RS}$ & $17.000,00$ & RS & $7.500,00$ \\
\hline$(-)$ CMV & $\mathrm{R} \$$ & $176.000,00$ & $\mathrm{RS}$ & 200.000,00 & $\mathrm{R} \$$ & $200.000,00$ \\
\hline (=) Lucro Bruto & R\$ & $56.400,00$ & R\$ & $63.000,00$ & $\mathrm{RS}$ & $72.500,00$ \\
\hline (=) Lucro Bruto / Vendas & & $20,14 \%$ & & $22,50 \%$ & & $25,89 \%$ \\
\hline
\end{tabular}

Fontes: dados da pesquisa. 
Figura 11 - Balancete comparativo com margem de lucro: 50\%

\begin{tabular}{|c|c|c|c|c|c|c|}
\hline \multicolumn{7}{|c|}{ BALANCETE COMPARATIVO COM MARGEM DE LUCRO: 50\% } \\
\hline \multirow{3}{*}{ CONTA } & \multicolumn{6}{|c|}{ REGIMES DE APURAÇÃO } \\
\hline & \multicolumn{2}{|c|}{ NORMAL } & \multicolumn{2}{|c|}{ SIMPLIFICADA } & \multicolumn{2}{|c|}{ SIMPLES } \\
\hline & \multicolumn{2}{|c|}{ SALDOS } & \multicolumn{2}{|c|}{ SALDOS } & \multicolumn{2}{|c|}{ SALDOS } \\
\hline Banco c/ Movimento & $\mathrm{R} \$ 460.000,00$ & & $\mathrm{R} \$ 460.000,00$ & & $\mathrm{R} \$ 460.000,00$ & \\
\hline Móveis e Utensílios & $\mathrm{R} \$ \mathbf{3 7 . 2 0 0 , 0 0}$ & & $\mathrm{R} \$ \mathbf{4 3 . 4 0 0 , 0 0}$ & & R\$ $40.800,00$ & \\
\hline Fornecedores & & $\mathrm{R} \$ 200.000,00$ & & $\mathrm{R} \$ 200.000,00$ & & $\mathrm{R} \$ 200.000,00$ \\
\hline ICMS a Pagar & & R\$ $24.200,00$ & & R\$ $20.400,00$ & & R\$ $\quad 8.300,00$ \\
\hline Capital Social Realizado & & $\mathrm{R} \$ 200.000,00$ & & $\mathrm{R} \$ 200.000,00$ & & $\mathrm{R} \$ 200.000,00$ \\
\hline Venda de Mercadoria & & $\mathrm{R} \$ 300.000,00$ & & $\mathrm{R} \$ 300.000,00$ & & $\mathrm{R} \$ \mathbf{3} 300.000,00$ \\
\hline Despesa com ICMS & $\mathrm{R} \$ \quad 51.000,00$ & & - & - & - & - \\
\hline CMV & $\mathrm{R} \$ 176.000,00$ & & $\mathrm{R} \$ 217.000,00$ & & $\mathrm{R} \$ 207.500,00$ & \\
\hline TOTAL & $\mathrm{R} \$ \mathbf{7 2 4 . 2 0 0 , 0 0}$ & $\mathrm{R} \$ \mathbf{7 2 4 . 2 0 0 , 0 0}$ & $\mathrm{R} \$ \mathrm{720.400,00}$ & $\mathrm{R} \$ \mathbf{7 2 0 . 4 0 0 , 0 0}$ & $\mathrm{R} \$ \mathbf{7 0 8 . 3 0 0 , 0 0}$ & $\mathrm{R} \$ \$ 708.300,00$ \\
\hline
\end{tabular}

Fonte: dados da pesquisa.

Figura 12 - Demonstração simplificada do resultado

\begin{tabular}{|c|c|c|c|c|c|c|}
\hline \multirow{2}{*}{ CONTA } & \multicolumn{6}{|c|}{ REGIMES DE APURAĞ̃ O } \\
\hline & \multicolumn{2}{|c|}{ NORMAL } & \multicolumn{2}{|c|}{ SIMPLIFICADA } & \multicolumn{2}{|c|}{ SIMPLES } \\
\hline Vendas & R\$ & $300.000,00$ & $\mathrm{R} \$$ & 300.000,00 & $\mathrm{R} \$$ & $300.000,00$ \\
\hline (-) ICMS s/Vendas & $\mathrm{RS}$ & $51.000,00$ & $\mathrm{RS}$ & $17.000,00$ & $\mathrm{RS}$ & $7.500,00$ \\
\hline$(-)$ CMV & $\mathrm{R} \$$ & $176.000,00$ & $\mathrm{RS}$ & 200.000,00 & $\mathrm{RS}$ & $200.000,00$ \\
\hline$(=)$ Lucro Bruto & R\$ & $73.000,00$ & $\mathrm{RS}$ & 83.000,00 & $\mathrm{R} \$$ & $92.500,00$ \\
\hline (=) Lucro Bruto / Vendas & & $24,33 \%$ & & $27,67 \%$ & & $30,83 \%$ \\
\hline
\end{tabular}

Fonte: dados da pesquisa. 
Figura 13 - Balancete comparativo com margem de lucro: $60 \%$

\begin{tabular}{|c|c|c|c|c|c|c|}
\hline \multicolumn{7}{|c|}{ BALANCETE COMPARATIVO COM MARGEM DE LUCRO: 60\% } \\
\hline \multirow{4}{*}{ CONTA } & \multicolumn{6}{|c|}{ REGIMES DE APURAÇÃO } \\
\hline & \multicolumn{2}{|c|}{ NORMAL } & \multicolumn{2}{|c|}{ SIMPLIFICADA } & \multicolumn{2}{|c|}{ SIMPLES } \\
\hline & \multicolumn{2}{|c|}{ SALDOS } & \multicolumn{2}{|c|}{ SALDOS } & \multicolumn{2}{|c|}{ SALDOS } \\
\hline & DEVEDOR & CREDOR & DEVEDOR & CREDOR & DEVEDOR & CREDOR \\
\hline Banco c/ Movimento & $\mathrm{R} \$ \$ 480.000,00$ & & $\mathrm{R} \$ \mathbf{4 8 0 . 0 0 0 , 0 0}$ & & $\mathrm{R} \$ \mathbf{4 8 0 . 0 0 0 , 0 0}$ & \\
\hline Móveis e Utensílios & $\mathrm{R} \$ \mathbf{3} \quad 37.200,00$ & & $\mathrm{R} \$ \quad 43.400,00$ & & $\mathrm{R} \$ \mathbf{4} \quad 40.800,00$ & \\
\hline Fornecedores & & $\mathrm{R} \$ 200.000,00$ & & $\mathrm{R} \$ \mathbf{2 0 0 . 0 0 0 , 0 0}$ & & $\mathrm{R} \$ \mathbf{2 0 0 . 0 0 0 , 0 0}$ \\
\hline ICMS a Pagar & & $\mathrm{R} \$ \mathbf{2 7 . 6 0 0 , 0 0}$ & & $\mathrm{R} \$ \mathbf{2} \quad 20.400,00$ & & $\mathrm{R} \$ \quad 8.300,00$ \\
\hline Capital Social Realizado & & $\mathrm{R} \$ 200.000,00$ & & $\mathrm{R} \$ 200.000,00$ & & $\mathrm{R} \$ \mathbf{2 0 0 . 0 0 0 , 0 0}$ \\
\hline Venda de Mercadoria & & $\mathrm{R} \$ 320.000,00$ & & $\mathrm{R} \$ 320.000,00$ & & $\mathrm{R} \$ 320.000,00$ \\
\hline Despesa com ICMS & $\mathrm{R} \$ \mathbf{5 4 . 4 0 0 , 0 0}$ & & - & - & - & - \\
\hline CMV & $\mathrm{R} \$ 176.000,00$ & & $\mathrm{R} \$ 217.000,00$ & & $\mathrm{R} \$ 207.500,00$ & \\
\hline TOTAL & $\mathrm{R} \$ 747.600,00$ & $\mathrm{R} \$ 747.600,00$ & $\mathrm{R} \$ 740.400,00$ & $\mathrm{R} \$ 740.400,00$ & $\mathrm{R} \$ 728.300,00$ & $\mathrm{R} \$ \mathbf{7 2 8 . 3 0 0 , 0 0}$ \\
\hline
\end{tabular}

Fonte: dados da pesquisa.

Figura 14 - Demonstração simplificada do resultado

\begin{tabular}{|c|c|c|c|c|c|c|}
\hline \multirow{2}{*}{ CONTA } & \multicolumn{6}{|c|}{ REGIMES DE APURAGÃO } \\
\hline & \multicolumn{2}{|c|}{ NORMAL } & \multicolumn{2}{|c|}{ SIMPLIFICADA } & \multicolumn{2}{|c|}{ SIMPLES } \\
\hline Vendas & R\$ & $320.000,00$ & $\mathrm{R} \$$ & $320.000,00$ & $\mathrm{R} \$$ & $320.000,00$ \\
\hline (-) ICMS s/Vendas & R\$ & $54.400,00$ & $\mathrm{RS}$ & $17.000,00$ & $\mathrm{RS}$ & $7.500,00$ \\
\hline$(-)$ CMV & $\mathrm{R} \$$ & 176.000,00 & $\mathrm{RS}$ & $200.000,00$ & $\mathrm{RS}$ & $200.000,00$ \\
\hline (=) Lucro Bruto & $\mathrm{RS}$ & $89.600,00$ & $\mathrm{RS}$ & $103.000,00$ & $\mathrm{RS}$ & $112.500,00$ \\
\hline (=) Lucro Bruto / Vendas & & $28,00 \%$ & & $32,19 \%$ & & $35,16 \%$ \\
\hline
\end{tabular}

Fonte: dados da pesquisa 